\title{
Performance Analysis, Modelling, and Development of a Signal Conditioning Unit of N-Type Metal Oxide Gas Sensor for Acetone Gas Detection.
}

ARUN K ( $\sim$ arunkbharath888@gmail.com )

NITC: National Institute of Technology Calicut https://orcid.org/0000-0003-4781-5744

\section{LEKSHMI M S}

NITC: National Institute of Technology Calicut

SUJAK J

NITC: National Institute of Technology Calicut

\section{Research Article}

Keywords: Acetone Gas sensor, COMSOL Multi- physics, Metal oxide semiconductor, Proteus Design Suite, Signal conditioning unit

Posted Date: April 15th, 2021

DOI: https://doi.org/10.21203/rs.3.rs-411075/v1

License: (9) This work is licensed under a Creative Commons Attribution 4.0 International License. Read Full License

Version of Record: A version of this preprint was published at Journal of Computational Electronics on July 6th, 2021. See the published version at https://doi.org/10.1007/s10825-021-01739-y. 


\title{
Performance analysis, modelling, and development of a signal conditioning unit of n-type metal oxide gas sensor for acetone gas detection.
}

\author{
Arun K • Lekshmi M S · Suja K J.
}

Received: date / Accepted: date

\begin{abstract}
Metal oxide semiconductors have been widely used in the field of gas sensor study. Various researches are being done to improve the sensitivity of the sensing material for applications like breath analyzers. In this work, a theoretical investigation and analysis of the ntype metal oxide for Acetone gas detection are carried out. The rate of change of resistance of the sensing material with respect to the change in the concentration of the target gas is analyzed. Acetone being a reducing gas the resistance was found to decrease for n-type material. The simulations were done using COMSOL Multiphysics and results showed that the resistance of the sensing layer varies with the concentration of the target gas. Also, the performance analysis of sensors has been compared with the experimental results. Further, we have also derived a mathematical expression connecting the relationship between the concentration of gas and the rate of change of resistance. The resistance change is observed to be proportional to the target gas concentration. A signal conditioning circuit was also designed for providing a user-friendly interface for monitoring the gas concentration. The simulation of the signal conditioning circuit was done using Proteus
\end{abstract}

Arun K

The Department of Electronics and Communication Engineering, National Institute of Technology Calicut, India

E-mail: arunkbharath888@gmail.com

Lekshmi M S

The Department of Electronics and Communication Engineering, National Institute of Technology Calicut, India

E-mail: lekshminairms@gmail.com

Suja K J

The Department of Electronics and Communication Engineering, National Institute of Technology Calicut, India

E-mail: suja@nitc.ac.in
Design Suite. This work will aid researchers to define and predict the behaviour of gas sensors.

Keywords Acetone Gas sensor - COMSOL Multiphysics · Metal oxide semiconductor · Proteus Design Suite $\cdot$ Signal conditioning unit

\section{Declaration}

Funding

The authors are thankful to DST-SERB, Government of India, for providing the financial support for this work.

\section{Conflict of interest}

The authors declare that they have no conflict of interest.

Availability of data and material

Not applicable

\section{Introduction}

The increase in pollution in the environment and its adverse effect on living organisms have drawn considerable attention towards the need for gas sensors [1]. There are different methods like resistive, acoustic, ultrasonic, thermoelectric, and electrochemical ones used for gas sensing. Among the different methods for gas sensing, resistive type-based gas sensors have gained a lot of research interest due to low cost, fabrication 
simplicity, and easy portability $[2,3]$. Metal oxide semiconductors are sensing materials used for gas sensors with resistive types. Metal oxides semiconductors are classified into two based on the type of charge carriers namely n-type and p-type. $\mathrm{ZnO}, \mathrm{SnO}_{2}, \mathrm{WO}_{3}$, etc are commonly used n-type semiconducting materials, and $\mathrm{NiO}, \mathrm{CuO}$, and $\mathrm{Co}_{2} \mathrm{O}_{3}$ are the p-type semiconducting materials [4]. They have been used for the detection of different types of gases like Hydrogen $\left(\mathrm{H}_{2}\right)$, Hydrogen sulphide $\left(\mathrm{H}_{2} \mathrm{~S}\right)$, Ammonia $\left(\mathrm{NH}_{3}\right)$, Carbon monoxide (CO), Volatile Organic Compounds (VOCs), etc [5, $6]$.

Metal oxide semiconductors with different geometries like nanotube, nanoflower, nanosphere, and hollow spheres have been synthesized [7,8]. The sensing layer helps to determine the selectivity and sensitivity of the sensor. Research work is mainly focussing on improving the selectivity and sensitivity of the sensor. Metal ions, metal oxide composites, and carbon materials are doped with the sensing layer, for enhancing the performance of the sensor.

The transmittal mechanism of these sensors is based on the variation of the resistance of the sensing layer. The redox reactions which are taking place on the surface of the sensors are the reason for the change in resistance [9]. A high-temperature environment is required for the redox reactions to take place. This temperature is provided with the help of a microheater. Different geometries like meander, double meander, spiral, circular, etc have been designed for the heater for optimizing the temperature distribution and also for reducing the power consumption [10]. The change in the resistance of the sensing layer is measured using an interdigitated electrode. The gas sensor performance is evaluated by considering the parameters such as recovery time, selectivity, sensitivity, response time, the limit of detection, and operating temperature respectively.

VOCs are emitted during day-to-day activities like cooking, building materials, driving a car, painting the house, or using pesticides [11]. These compounds have an adverse effect on human health even when exposed to low concentration. The human breath also contains VOCs which are an important breath marker for many diseases like kidney failure, diabetes, Asthma, etc [12]. Acetone is one of the important VOC present in the human breath which is a breath marker for diabetes mellitus. A healthy person has 0.2 to 1.8 ppm concentration of Acetone in his breath. Acetone concentration above $1.8 \mathrm{ppm}$ indicates diabetes condition. If the concentration is above $25 \mathrm{ppm}$, then it's the acute case of diabetes mellitus [13-15]. Also in laboratories and industries, Acetone is used as a common liquid. When exposed to a high concentration of Acetone leads to nausea, headache, fatigue, and nervous system damage. So as a safety concern, the environmental concentration of Acetone monitoring is necessary [16].

Performance parameters of the gas sensor have been observed by using COMSOL Multiphysics. For n-type the properties of $\mathrm{ZnO}$ are used. Theoretical analysis and investigation of the sensing characteristics of $\mathrm{ZnO}$ gas sensors towards Acetone gas are performed. The effect of concentration on the rate of variation of resistance of the sensing layer was also analyzed. A signal conditioning circuit was also designed for providing a user-friendly interface for monitoring the gas concentration.

\section{Gas sensing Mechanism}

Metal oxide gas sensors detect the target gas due to the changes in their electrical resistance [17]. This change happens due to the various adsorption and desorption process taking place on the sensing layer surface. These results in the change in the concentration of the charge carrier. When the metal oxide comes in contact with the atmosphere, the molecules of Oxygen that are absorbed over the surface educed the electrons from the conduction band. As a result, ions are formed due to the trapped electrons. Due to the falling off of the density of the electrons over the surface, an electron depletion layer is formed and a barrier potential is formed. The chemisorbed ions of oxygen formed depend on the operating temperature of the gas sensors. The following equations summarise the oxygen adsorption mechanism [18].

$\mathrm{O}_{2 \text { (gas) }} \longrightarrow \mathrm{O}_{2}(\mathrm{ads})$

$\mathrm{O}_{2 \text { (gas) }}+\mathrm{e}^{-} \longleftrightarrow \mathrm{O}_{2}^{-}$(ads) $\quad\left(<100{ }^{0} C\right)$

$\mathrm{O}_{2}^{-}($ads $)+\mathrm{e}^{-} \longleftrightarrow 2 \mathrm{O}^{-}($ads $) \quad\left(<100-300{ }^{0} C\right)$

$\mathrm{O}^{-}(\operatorname{ads})+\mathrm{e}^{-} \longleftrightarrow \mathrm{O}^{2-}(\operatorname{ads}) \quad\left(>300{ }^{0} C\right)$

When the sensor is then disclosed to the target gas, the surface is getting absorbed by molecules of gas and then reacts with adsorbed ions of oxygen. The increase or decrease in resistance depends on the majority carriers in the metal oxide semiconductor [19]. The reaction of Acetone gas with the adsorbed oxygen ions is given by the equation (5) [20]: 


$$
\mathrm{CH}_{3} \mathrm{COCH}_{3} \text { (gas) }+8 \mathrm{O}^{-} \longrightarrow 3 \mathrm{CO}_{2}+3 \mathrm{H}_{2} \mathrm{O}+8 \mathrm{e}^{-}
$$

When $\mathrm{ZnO}$ is exposed to air, oxygen adsorption takes place and the resistance of the metal oxide layer increases due to the removal of electrons [21]. A schematic demonstration of this is shown in Fig.1a. As a result, an increase in depletion layer width has occurred as illustrated in Fig.1b. When Acetone gas is fed through the chamber, the gas molecules react with the adsorbed oxygen ions. Acetone being a reducing gas causes the resistance of the sensing layer to decrease as the adsorbed electrons are injected back into the electron depletion layer [22]. This is shown schematically in Fig.1c. and the corresponding decrease in the potential barrier due to the injection of the adsorbed electrons back into the conduction band is shown in Fig.1d.

\section{Architecture of gas sensor}

The schematic representation of the proposed gas sensor is shown in Fig.2. The proposed gas sensor consists of the following parts:

- The substrate is Silicon with 0.8 x 1 x $0.5 \mathrm{~mm}$ dimensions. It should well adhere to metal and have high mechanical stability.

- Meander-shaped Platinum heater with a dimension of $0.8 \times 0.5 \times 0.001 \mathrm{~mm}$ for providing the operating temperature.

- An insulating layer made up of silicon dioxide with dimensions $0.8 \times 0.5 \times 1 \mathrm{~mm}$ for preventing direct contact between the heater and the electrode.

- The resistance measurement is done using the electrode with a dimension of $0.8 \times 0.5 \times 0.5 \mathrm{~mm}$. Platinum is the material used for the electrode.

- The sensing layer of the sensor consists of a $1 \mathrm{~mm}$ thick $\mathrm{ZnO}$ for n-type sensor.

\section{Finite element analysis}

COMSOL Multiphysics was used for simulating the gas sensor. The gas chamber model, heat transfer model, and conducting model were the models simulated for analyzing the performance of the sensor.

\subsection{Gas Chamber model}

The gas chamber model is shown in Fig.3a. A cylindrical chamber with a radius and height of $16 \mathrm{~mm}$ with one inlet and two outlets of a diameter of about $2 \mathrm{~mm}$ and $1 \mathrm{~mm}$ respectively are designed. The chamber is used to study the conductivity variation of the sensing layer when exposed to the Acetone gas. The gas is applied to the chamber from the upper base and is collected out from the other end with the help of two outlets for the easy outward flow of the gas from the chamber. Fig.3b depicts the gas flow distribution in the chamber.

\subsection{Heat transfer model}

The operating temperature for the working of the gas sensor is provided by using a microheater. The schematic representation of microheater inside the chamber is shown in Fig.4a. The simulated microheater showed in Fig.4b. Platinum is the heating material used for the microheater due to its advantage like low power consumption [23]. To obtain the required temperature, DC voltage in the range of 0.1 to $5 \mathrm{~V}$ is applied. Meander geometry is chosen for the microheater for obtaining a uniform temperature distribution of heat on the sensing layer.

The platinum properties which are used in the simulation are shown in Table 1

Table 1 Properties of Platinum

\begin{tabular}{|l|l|l|l|l|}
\hline $\begin{array}{l}\text { Electrical } \\
\text { Conductivity } \\
(\mathrm{S} / \mathrm{m})\end{array}$ & $\begin{array}{l}\text { Coefficient of } \\
\text { thermal expansion } \\
(1 / \mathrm{K})\end{array}$ & $\begin{array}{l}\text { Density } \\
\left(\mathrm{kg} / \mathrm{m}^{3}\right)\end{array}$ & $\begin{array}{l}\text { Youngs } \\
\text { modulus } \\
(\mathrm{GPa})\end{array}$ & $\begin{array}{l}\text { Poissons } \\
\text { Ratio }\end{array}$ \\
\hline $8.9 \times 10^{6}$ & $8.80 \times 10^{-6}$ & 21450 & 168 & 0.38 \\
\hline
\end{tabular}

The distribution of heat over the surface of the heater at a voltage of $5 \mathrm{~V}$ is shown in Fig.5a and the variation of temperature with respect to the applied input voltage of the heater shown in Fig.5b

\subsection{Conducting model}

Metal oxide semiconductors undergo a change in their resistance when exposed to the target gas. This property is used for gas sensors. The variation in resistance depends on the type of metal oxide used for gas sensing and it is achieved by the adsorption and desorption processes. The change in resistance is also analyzed as a function of temperature and concentration of gas.

\subsubsection{Numerical simulation conditions for the conducting model}

Solid mechanics module, heat transfer module, electrical module and chemical transport species module are the physics used for the simulation of gas sensors. The 


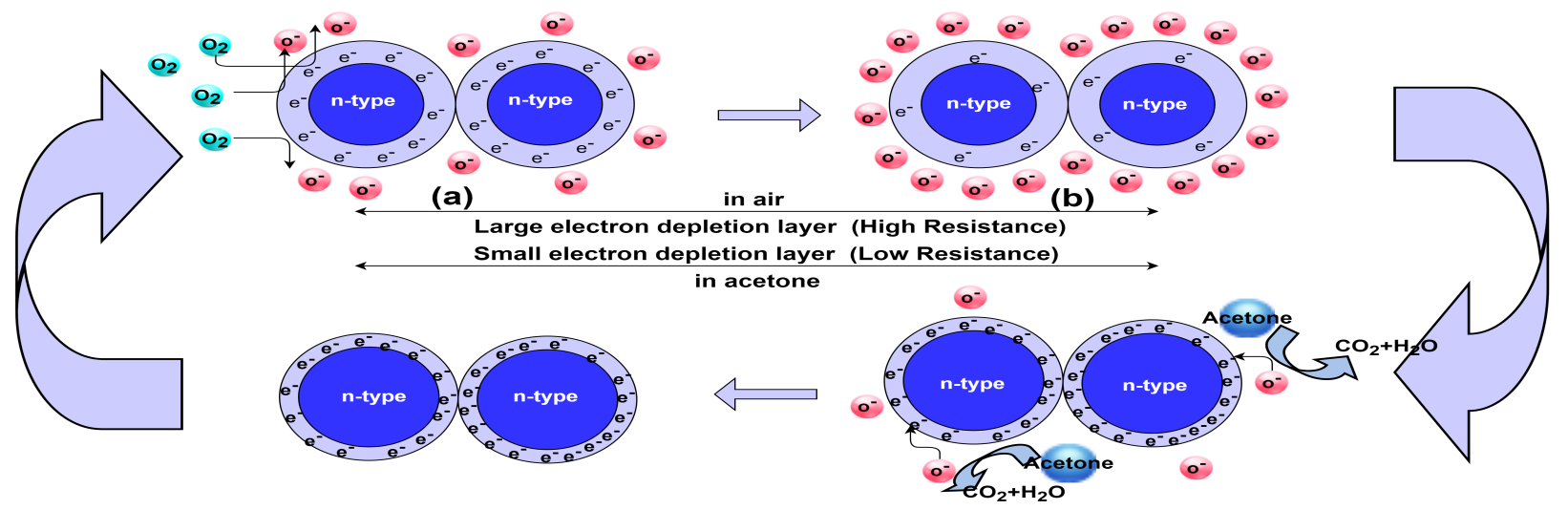

(d)

(c)

Fig. 1 Schematic showing (a) ZnO reaction with the oxygen (b) depletion layer width increases (c) gas sensing mechanism with the acetone gas (d) decrease in potential barrier.

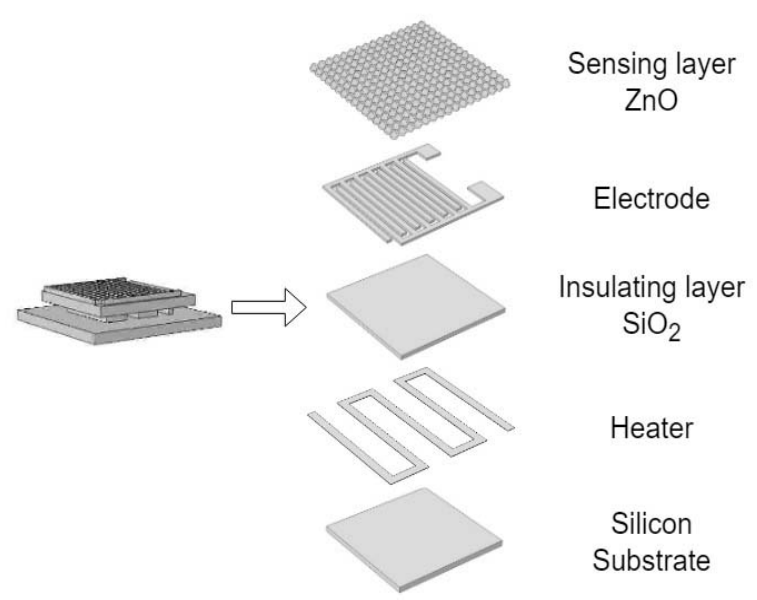

Fig. 2 Architecture view model of gas sensor.

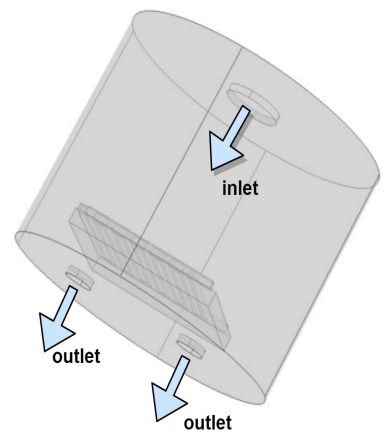

(a)

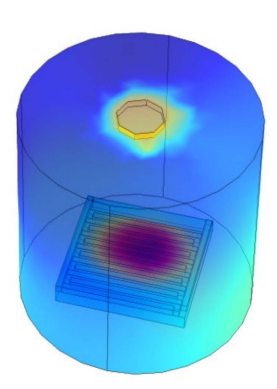

(b)
Fig. 3 Schematic representation of (a) chamber with sensor (b) gas flow distribution in the chamber.

gas flow in the chamber is modelled using Navier Stokes equation given by [24],

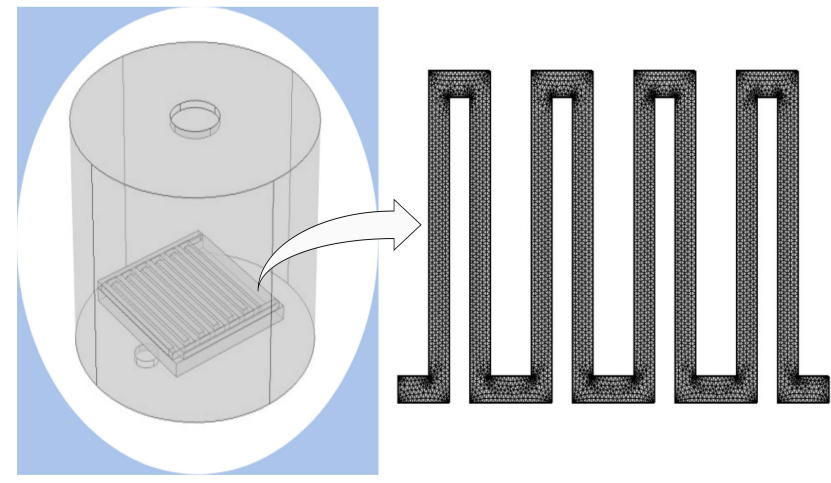

(a)

(b)

Fig. 4 (a)Schematic representation of microheater inside the chamber (b) Simulated microheater.

$\rho \frac{D \vec{U}}{D t}=-\nabla P+\rho g+\eta \nabla^{2} U$

where $\rho, \mathrm{g}, \mathrm{U}, \eta$, and $\mathrm{P}$ are gas flux, gravity, velocity field, viscosity, and gas pressure, respectively. The above equation is solved using continuity equation for achieving the gas field velocity which is given by [25],

$\frac{\delta \rho}{\delta t}+\nabla(\rho \vec{U})=0$

When the gas has an incompressible flow $\rho$ becomes zero. Therefore the equation reduces to,

$\nabla \vec{U}=0$

The boundary conditions of the inlet and outlet pressure are given by [26], 


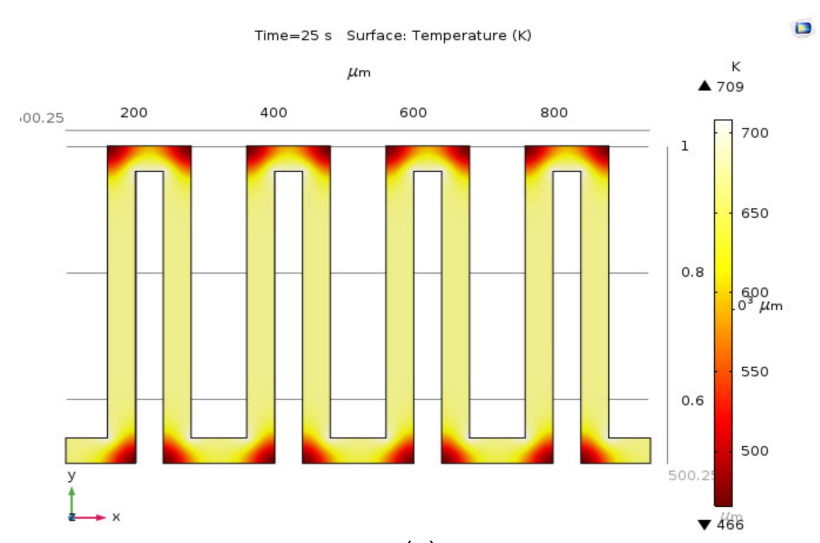

(a)

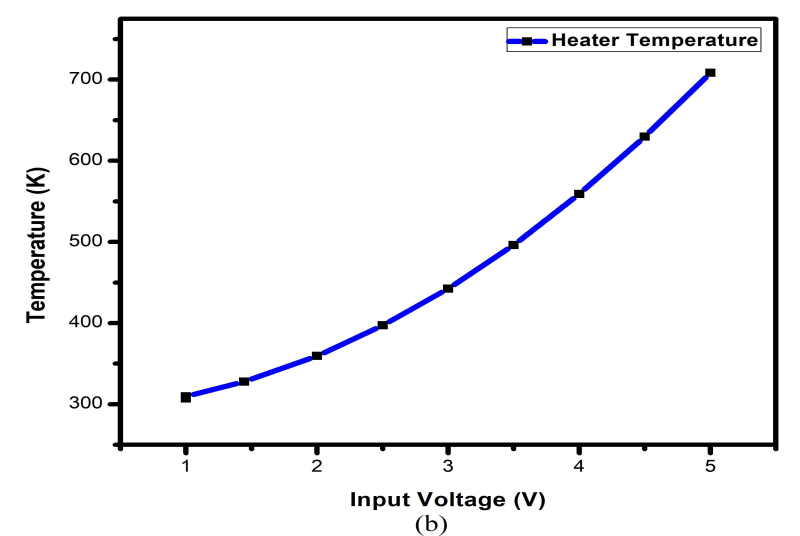

Fig. 5 (a) Heat distribution on the surface of the heater (b) Heater temperature versus applied input voltage.

$$
\begin{aligned}
P_{\text {inlet }} & =0 \\
P_{\text {outlet }} & =0
\end{aligned}
$$

In the heat transfer model, the heat from the heater of the sensor is transferred to the sensing layer through conduction. The heat transfer in solids is given by [27],

$$
q=-k \nabla T
$$

where $\mathrm{q}$ is the flux density, $\mathrm{k}$ is the electrical conductivity and $\mathrm{T}$ is the temperature respectively. Also, there will be heat loss to the surrounding air and the device edges by radiation and convection. This phenomenon is described using Neumann's law of cooling [28],

$q_{0}=h\left(T_{\text {sur }}-T_{\text {air }}\right)$

where $q_{0}$ is the heat transferred, $\mathrm{h}$ is the heat transfer coefficient, $T_{\text {sur }}$ and $T_{\text {air }}$ is the surface and air temperature respectively.

For electrical model, the reaction between the gas molecules and the sensing surface is modeled using poisson's equation [29],

$\nabla^{2} V=0$

As the sensing layer is shielded from the surrounding environment, the condition at the boundary for the current density is given by [32],

$m . J=0$

where $\mathrm{m}$ is the normal vector of the plane of the active layer and $\mathrm{J}$ is the current density.

\subsubsection{Response of gas sensor}

The Scanning Electron Microscopic characterization of synthesized $\mathrm{ZnO}$ nanoparticles was found to have spherical structure are shown in Fig.6 [31]. and the same has

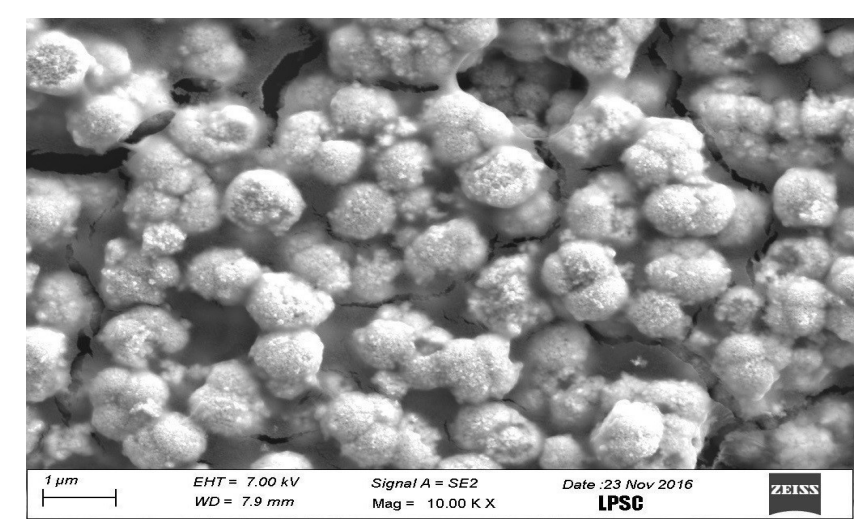

Fig. 6 SEM image of Zinc Oxide ( $\mathrm{ZnO})$

been used for simulating the sensing layer. When the oxygen adsorption takes place the electrons are removed from the sensing layer and as a result, a depletion layer is formed. As a result, the resistance of the $\mathrm{ZnO}$ layer increases. When Acetone gas is fed to the chamber, it reacts with the oxygen adsorbed and releases electrons. This will reduce the electron depletion layer and causes a decrease in the resistance of the $\mathrm{ZnO}$ layer. The variation of the resistance of the $\mathrm{ZnO}$ at different concentrations of the sensing layer is shown in Fig.7.

Table 2 shows the properties of the Zinc oxide

Table 2 Properties of the Zinc oxide

\begin{tabular}{|l|l|l|l|}
\hline $\begin{array}{l}\text { Material } \\
\text { Type }\end{array}$ & $\begin{array}{l}\text { Thermal } \\
\text { Conductivity } \\
(\mathrm{W} / \mathrm{mK})\end{array}$ & $\begin{array}{l}\text { Youngs } \\
\text { modulus } \\
(\mathrm{GPa})\end{array}$ & $\begin{array}{l}\text { Density } \\
\left(\mathrm{kg} / \mathrm{m}^{3}\right)\end{array}$ \\
\hline $\mathbf{Z n O}$ & 6 & 210 & 5676 \\
\hline
\end{tabular}




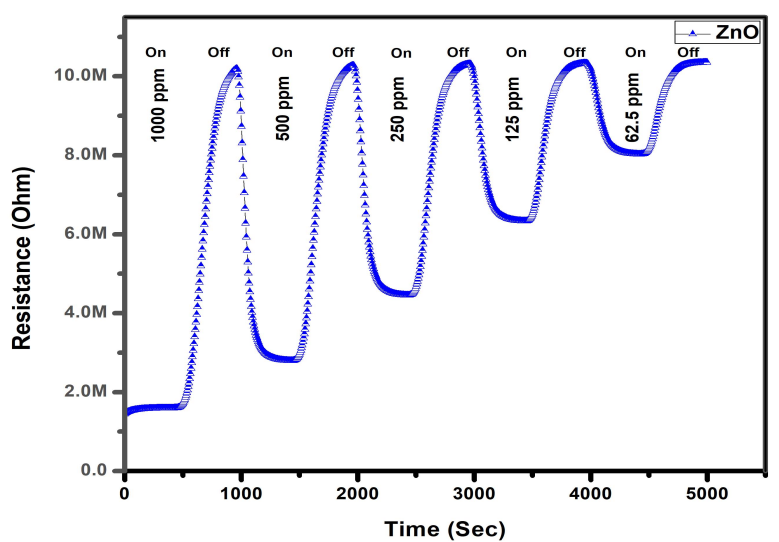

Fig. 7 The variation of reistance of $\mathrm{ZnO}$ at different concentration of Acetone gas

Due to the adsorption of Acetone over the surface of the oxide layer the resistance changes. The resistance of the sensing layer in the presence of Acetone is represented by $R_{\text {acetone }}$ and the resistance in the presence of air is represented by $R_{a i r}$. Hence the response of the gas sensor for n-type is given by the equation (14) [32],

Response $_{\text {ntpye }}=R_{\text {air }} / R_{\text {acetone }}$

The Time versus Response graphs for $\mathrm{ZnO}$ is shown in Fig.8.

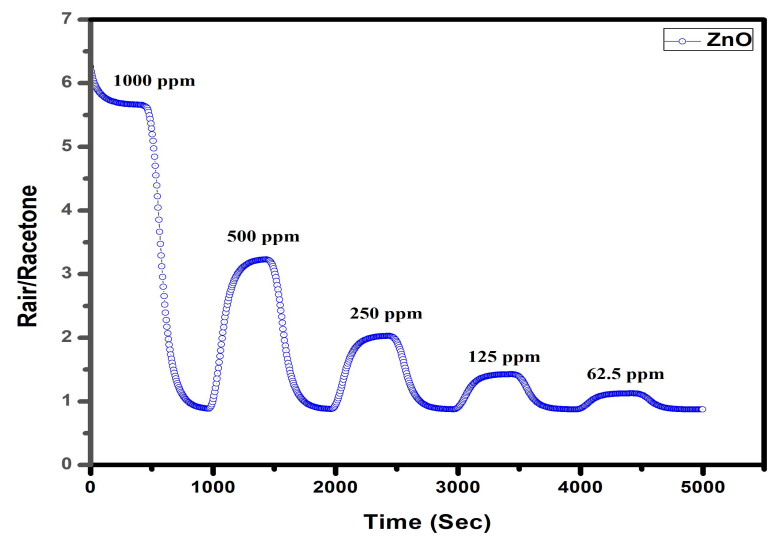

Fig. 8 The Time versus Response of $\mathrm{ZnO}$ at different concentration of Acetone gas

\section{Experimental method}

The experimental setup for the sensing of acetone gas is shown in Fig.9. The metal oxide nanomaterials synthesized were coated on the interdigitated electrode. The sensor was placed in a vacuum chamber.

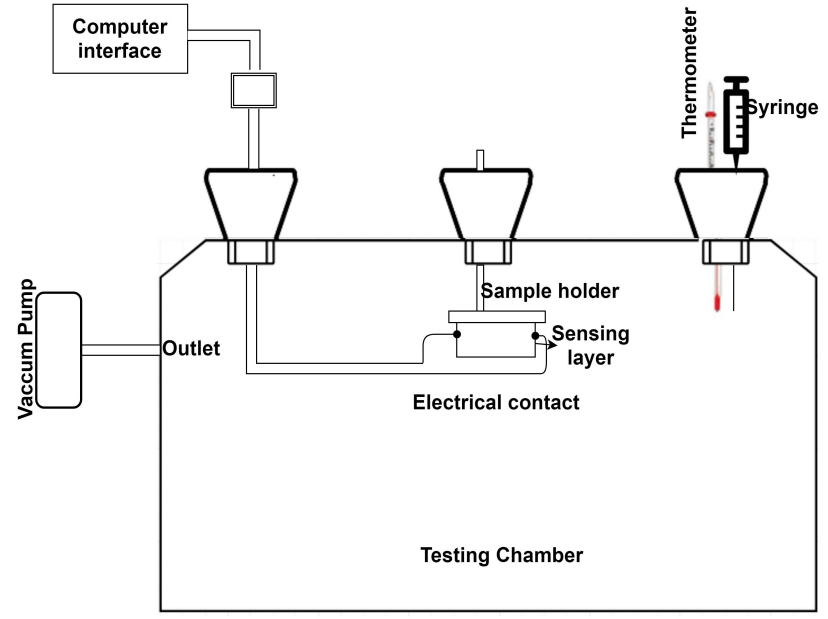

Fig. 9 Schematic diagram of experimental sensing setup

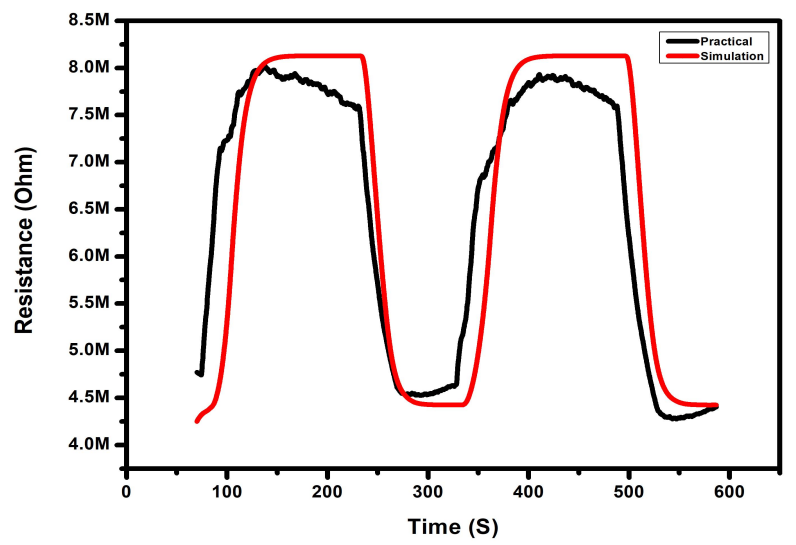

Fig. 10 The comparison between practical and simulation data for the variation of resistance of $\mathrm{ZnO}$ at a concentration $1000 \mathrm{ppm}$ of Acetone gas

The desired concentration of acetone vapor is obtained by injecting the Acetone liquid of a particular volume into the chamber. The volume of Acetone in ppm is determined using the equation (15) [33]

$C_{p p m}=\frac{\delta V_{T} R T}{M P V}$

Where $\delta$ is the density of target liquid $(\mathrm{g} / \mathrm{mL}), V_{T}$ is the volume of liquid $\mu \mathrm{L}, \mathrm{R}$ is the gas constant, $\mathrm{T}$ is the temperature $(\mathrm{K}), \mathrm{M}$ is the molecular weight, $\mathrm{P}$ is the chamber pressure(atm) and $\mathrm{V}$ is the volume of the chamber in litre. The experimental data is validated with the simulation data for $1000 \mathrm{ppm}$ concentration of acetone and is shown in Fig.10. The response graph for the same concentration is shown in Fig.11. 


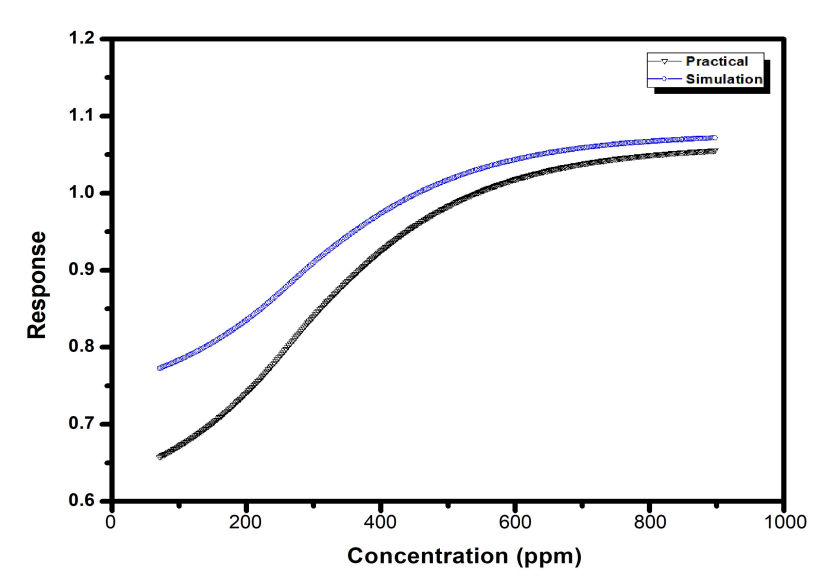

Fig. 11 The Concentration versus Response of $\mathrm{ZnO}$.

\section{Analytical approach for the rate of change of resistance}

The rate of change of resistance is high for a higher concentration of Acetone gas as the adsorption will be more. Moreover, the maximum rate of change will occur immediately after turning on or turning off of Acetone gas flow. An exponential growth behaviour is observed in all the resistance-time graphs. Furthermore the conductivity $\sigma$ is given by [34],

$\sigma=n \mu_{n} q+p \mu_{p} q$

where $\mathrm{n}$ is the carrier concentration of electrons, $\mathrm{p}$ is the carrier concentration of holes, $\mu_{n}$ is the drift velocity of electrons, $\mu_{p}$ is the drift velocity of holes and $q$ is the charge.

As the adsorption takes place, the conductance of the sensing layer can be expressed as,

$$
\sigma_{\text {sensing }}=(n-\alpha C t) \mu_{n} q+(p+\alpha C t) \mu_{p} q
$$

where $\alpha$ is the adsorption coefficient and $\mathrm{C}$ is the concentration of the target gas. Equation (17) shows the subjection of the sensing layer to an Acetone gas concentration for a short time. As resistivity is the inverse of conductance it can be expressed as,

$\rho=\frac{1}{\sigma}=\frac{1}{(n-\alpha C t) \mu_{n} q+(p+\alpha C t) \mu_{p} q}$

If $n=p$ the rate of change can be expressed as,

$\frac{d \rho}{d t}=-\frac{-\alpha C \mu_{n} q+\alpha C \mu_{p} q}{\left((n-\alpha C t) \mu_{n} q+(n+\alpha C t) \mu_{p} q\right)^{2}}$

If $\alpha \mathrm{Ct}$ is very much smaller than $\mathrm{n}, \alpha \mathrm{Ct}<<\mathrm{n}$, the rate of change can be expressed as

$\frac{d \rho}{d t} \cong \frac{\alpha C\left(\mu_{n}-\mu_{p}\right)}{n^{2} q\left(\mu_{n}+\mu_{p}\right)^{2}}$
As the resistance related to the cross sectional area $\mathrm{A}$ and length 1 the equation can be written as

$\frac{A}{l} \frac{d R}{d t}=\frac{\alpha C\left(\mu_{n}-\mu_{p}\right)}{n^{2} q\left(\mu_{p}+\mu_{p}\right)^{2}}$

Since all the parameters are constants, it can be shown that rate of resistance change is proportional to concentration of the gas.

$\frac{d R}{d t} \propto \alpha C$

\subsection{Adding donor impurity}

Similarly, if we are adding impurities to the sensing layer the equations can be modified. If adding a Donor impurity with donor carrier concentration, $N_{D}$ the equation (16) can be changes to

$\sigma=N_{D} \mu_{n} q+p \mu_{p} q$

As the adsorption takes place, the conductance of sensing layer can be expressed as,

$\sigma_{\text {sensing }}=\left(N_{D}-\alpha C t\right) \mu_{n} q+(p+\alpha C t) \mu_{p} q$

If $N_{D}$ is very much larger than $\alpha \mathrm{Ct}, N_{D}>>\alpha \mathrm{Ct}$, the rate of change can be expressed as

$\frac{d \rho}{d t} \cong \frac{\alpha C\left(\mu_{n}-\mu_{p}\right)}{q\left(N_{D} \mu_{n}+p \mu_{p}\right)^{2}}$

Similar to equation (21)

$\frac{A}{l} \frac{d R}{d t}=\frac{\alpha C\left(\mu_{n}-\mu_{p}\right)}{q\left(N_{D} \mu_{n}+p \mu_{p}\right)^{2}}$

Since all the parameters are constants, it can be shown that rate of resistance change is proportional to concentration of the gas.

$\frac{d R}{d t} \propto \alpha C$

According to equations (22) and (27) the maximum value of $\frac{d R}{d t}$, is directly proportional to the concentration of the target gas. The first-order derivative curve at a particular concentration of Acetone gas for $\mathrm{ZnO}$ is shown in Fig.12. 


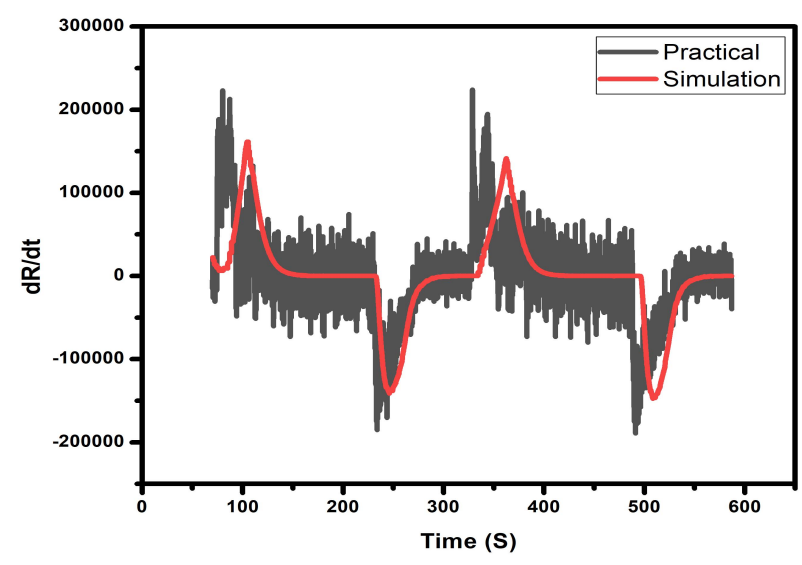

Fig. 12 First order derivative curve of resistance time curves of $\mathrm{ZnO}$ sensor at a concentration of $1000 \mathrm{ppm}$.

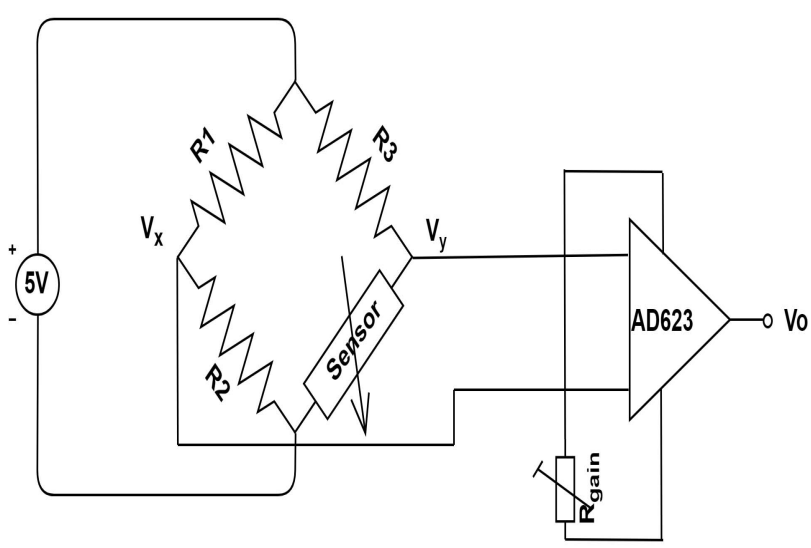

Fig. 13 Circuit diagram of signal conditioning unit

\section{Signal conditioning unit}

The simulated gas sensor resistance varies between a few $\mathrm{M} \Omega$ ranges depending upon the concentration of the gas present. It needs a dynamic measurement technique for the accurate readout of these resistance changes. A signal conditioning unit is simulated for this purpose can be utilized for n-type gas sensors. It contains a bridge circuit followed by a low signal amplifier shown in the Fig.13.

When contact with the target gas, the conductance of the sensing material changes, accordingly it shows a detectable variation in its resistance. These resistance variations are detected by a Wheatstone bridge circuitry, which includes three standard resistors, $R_{1}, R_{2}$, $R_{3}$, and one sensor. The bridge output voltage changes according to the resistance of the sensing layer. The output of the bridge is connected to a low signal amplifier. This work uses an AD623 instrumentation amplifier as a low signal amplifier [35]. To ensures the single and dual supply operations it is a modified version of the classic 3 opamp instrumentation amplifier. It offers a different set of gain values by connecting an external resistance. The output equation of this amplifier is defined as follows.

$V_{o}=\left(1+\frac{100 k \Omega}{R_{\text {gain }}}\right)\left(V_{x}-V_{y}\right)$

Where $\mathrm{V}_{0}$ is the output voltage of the amplifier, $\mathrm{V}_{x}$ is the non-inverting terminal voltage, $\mathrm{V}_{y}$ is the inverting terminal voltage $\mathrm{R}_{\text {gain }}$ is the external gain controlling resistance. For getting a particular gain it needs to calculate the value of the resistance by the equation,

$R_{\text {gain }}=\frac{100 k \Omega}{(\text { Gain }-1)}$

The resistance variation is due to the adsorption of Acetone gas on the $\mathrm{ZnO}$ is observed in the range of $1 \mathrm{M} \Omega$ to $10 \mathrm{M} \Omega$, for analyzing the performance of the sensor over this range the gain is selected as 1.5 by choosing the $\mathrm{R}_{\text {gain }}$ as $200 \mathrm{k} \Omega$. The simulation is done using Proteus Design Suite software. The simulated signal conditioning unit with ADC output is shown in Fig.14. In the simulation, the Arduino Uno board is used for the ADC conversion it has an inbuilt resolution of $4.9 \mathrm{mV}$ per unit 5/1024.

The concentration of acetone gas is varied from 1000 ppm to $62.5 \mathrm{ppm}$ and the corresponding resistance, output voltage, and the ADC output values for the $\mathrm{ZnO}$ are shown in table 3 .

Table 3 Signal conditioning output for n-type sensor

\begin{tabular}{|l|l|l|l|}
\hline $\begin{array}{l}\text { Gas } \\
\text { concentration } \\
(\mathrm{ppm})\end{array}$ & $\begin{array}{l}\text { Sensor } \\
\text { resistance } \\
\text { average } \\
(\mathrm{M} \Omega)\end{array}$ & $\begin{array}{l}\text { Signal conditioning } \\
\text { Output } \\
\text { voltage } \\
(\mathrm{V})\end{array}$ & $\begin{array}{l}\text { ADC } \\
\text { numeric } \\
\text { digital } \\
\text { output }\end{array}$ \\
\hline 1000 & 1.56 & 3.18 & 650 \\
500 & 4.06 & 2.22 & 456 \\
250 & 4.72 & 2 & 410 \\
125 & 6.68 & 1.44 & 296 \\
62.5 & 8.18 & 1.09 & 223 \\
\hline
\end{tabular}

It is observed that at a higher Acetone gas concentration of $1000 \mathrm{ppm}$ the resistance was $\sim 1.56 \mathrm{M} \Omega$ with the corresponding output voltage of $3.18 \mathrm{~V}$ and at the lower gas concentration, the resistance was $\sim$ $8.18 \mathrm{M} \Omega$ and the corresponding output voltage was 1.09 $\mathrm{V}$. Therefore as the input gas concentration decreases the resistance value increases, the output voltage decreases, accordingly, the ADC value decreases. 


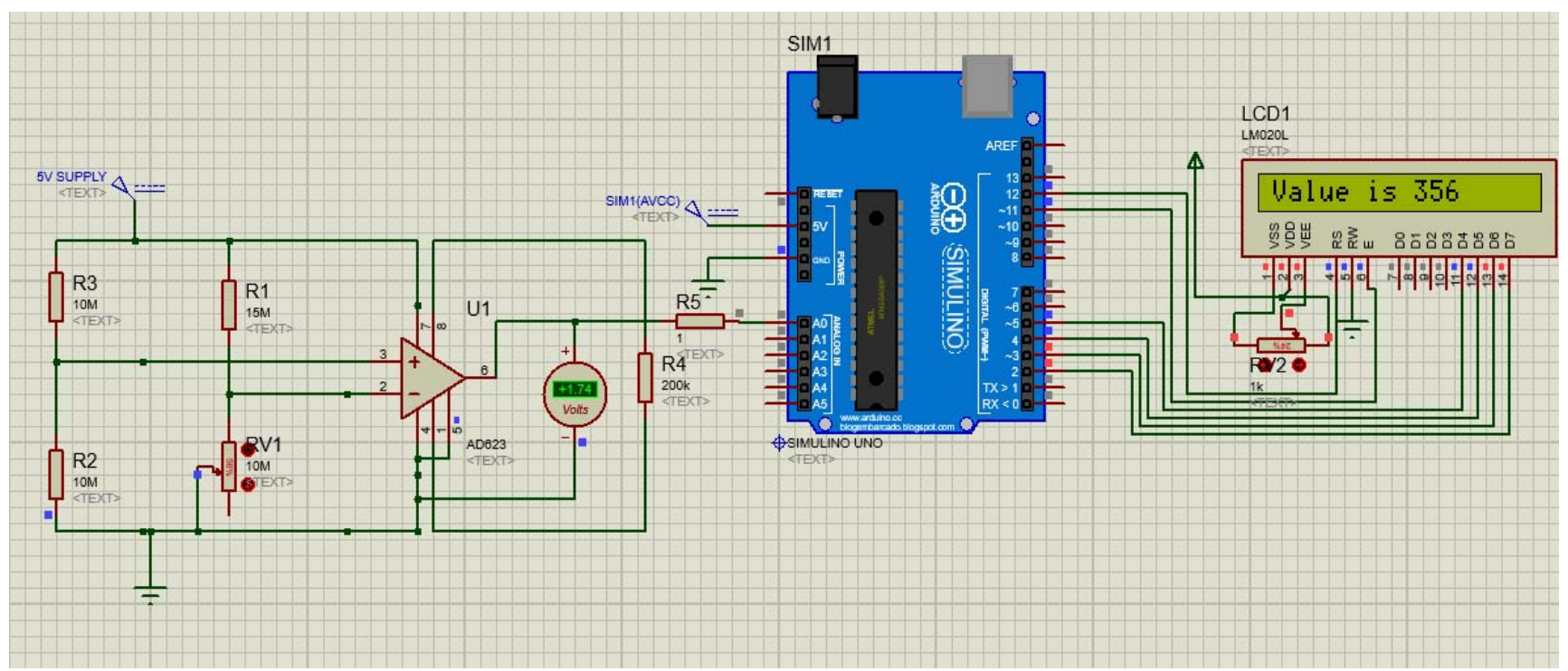

Fig. 14 Signal conditioning unit with ADC

\section{Comparison of the proposed work with the reported results of References [24] and [34]}

The proposed work developed a feasible method to rapidly determine the concentration of target gas for metal oxide semiconductors considering the donor impurities separately. The work reported in the literature [24] for the detection of reducing gas has not given any significance for the measurement of the concentration of target gas. But the proposed work developed a microcontroller based signal conditioning unit with the sensor output for efficient detection of the target gas. Despite finite element simulation tool COMSOL being increasingly used for the simulation of the sensing mechanism in the gas sensors, there is no modeling for the rate of change of resistance with the gas concentration and simulation of signal conditioning unit for the measurement of the concentration of target gas. Analytical evaluation is very much useful for determining the general properties of a gas sensor. Chiu Hsien and et al, [34] reported a general approach on the relationship between the rate of the change of resistance $\mathrm{dr} / \mathrm{dt}$ and gas concentration. In this work, it is separately analyzed for an n-type metal oxide gas sensor for reducing gas.

\section{Conclusion}

Performance analysis of metal oxide semiconductors with $\mathrm{ZnO}$ as a sensing material has been presented in this work. The optimum operating temperature of the sensing layer is provided by using a microheater with meander geometry. The sensing response for the n-type sensor was observed at different gas concentrations. The performance of the gas sensors has been observed by using the simulation software and has been verified with the experimental data. Developed a mathematical expression for the rate of change of resistance at different concentrations of the Acetone, and it is found to be proportional to the gas concentration. A signal conditioning circuit was also developed for accurately reading the measured resistance change. For n-type metal oxide, a higher ADC value indicates a higher concentration of Acetone. The presented model and signal conditioning unit in this work are capable of analyzing the performance of any n-type of gas sensors made with metal oxide.

\section{Acknowledgements}

The authors are thankful to DST-SERB, Government of India, for providing the financial support for this work. The authors are also thankful to LPSC, ISRO for providing the SEM image.

\section{References}

1. George F Fine, Leon M Cavanagh, Ayo Afonja and Russel Binions, "Metal Oxide Semiconductor Gas Sensors in Environmental Monitoring", Sensors, vol. 10, no. 6, pp. 54695502, June 2010.

2. $\mathrm{Xu}, \mathrm{Ke}$ and $\mathrm{Fu}$, Chuhan and Gao, Zhijun and Wei, Fanan and Ying, $\mathrm{Yu}$ and $\mathrm{Xu}$, Chong and $\mathrm{Fu}$, Guojiang,"Nanomaterial-based gas sensors: A review" Instrumentation Science \& Technology, vol. 46, no. 2, pp. 115-145, Jul. 2018.

3. Yuan, Zhenyu and Li, Rui and Meng, Fanli and Zhang, Junjie and Zuo, Kaiyuan and Han, Erchou , "Approaches 
to Enhancing Gas Sensing Properties: A Review" Sensors, vol. 19, no. 7, pp. 1495, March. 2019.

4. Ji, Haocheng and Zeng, Wen and Li, Yanqiong, "Gas sensing mechanisms of metal oxide semiconductors: a focus review", Nanoscale, vol. 11, pp. 22664-22684, Oct. 2019.

5. Mokoena, Teboho P and Swart, Hendrik C and Motaung, David E, "A review on recent progress of p-type nickel oxide based gas sensors: future perspectives", Journal of Alloys and Compounds, vol. 805, pp. 267-294. Jun. 2019.

6. Wang, Chao and Zhu, Junwu and Liang, Shiming and Bi, Huiping and Han, Qiaofeng and Liu, Xiaoheng and Wang, Xin, "Reduced graphene oxide decorated with $\mathrm{CuO}-\mathrm{ZnO}$ hetero-junctions: towards high selective gas-sensing property to acetone", Journal of Materials Chemistry A, vol. 2, no. 43, pp. 18635-18643, Sept. 2014.

7. Wang, Shuangming and Cao, Jing and Cui, Wen and Fan, Longlong and $\mathrm{Li}$, Xifei and $\mathrm{Li}$, Dejun, "Facile synthesis of bamboo raft-like $\mathrm{Co} 3 \mathrm{O} 4$ with enhanced acetone gas sensing performances", Journal of Alloys and Compounds, vol. 758, pp. 45-53, Aug. 2018.

8. Cao, Jing and Wang, Shuangming and Zhang, Haiming and Zhang, Tong, "Facile construction of $\mathrm{Co} 3 \mathrm{O} 4$ porous microspheres with enhanced acetone gas sensing performances", Materials Science in Semiconductor Processing, vol. 101, pp. 10-15, May 2019.

9. Sun, Yu-Feng and Liu, Shao-Bo and Meng, Fan-Li and Liu, Jin-Yun and Jin, Zhen and Kong, Ling-Tao and Liu, Jin-Huai, "Metal oxide nanostructures and their gas sensing properties: a review", Sensors, vol. 12, no. 3, pp. 2610-2631, Feb. 2012.

10. Nivedita and Anil Arora, "Design of MEMS Microheater Based $\mathrm{H}_{2}$ Gas Sensor", International Journal of Advanced Research in Computer Engineering \& Technology, vol. 5, no. 5, pp. 1467-1470, May 2016.

11. Mirzaei, Ali and Leonardi, SG and Neri, Giovanni, "Detection of hazardous volatile organic compounds (VOCs) by metal oxide nanostructures-based gas sensors: A review", Ceramics international, vol. 42, no. 14, pp. 15119-15141. June 2016.

12. Baharuddin, Aainaa Aqilah and Ang, Bee Chin and Haseeb, ASMA and Wong, Yung Cheng and Wong, Yew Hoong, "Advances in chemiresistive sensors for acetone gas detection", Materials Science in Semiconductor Processing, vol. 103, pp. 104616, July 2019.

13. Amiri, Vahid and Roshan, Hossein and Mirzaei, Ali and Neri, Giovanni and Ayesh, Ahmad I, "Nanostructured Metal Oxide-Based Acetone Gas Sensors: A Review", Sensors, vol. 20, no. 11, pp. 3096, May 2020.

14. Wang, Shuangming and Cao, Jing and Cui, Wen and Fan, Longlong and Li, Xifei and Li, Dejun and Zhang, Tong, "One-dimensional porous $\mathrm{Co} 3 \mathrm{O} 4$ rectangular rods for enhanced acetone gas sensing properties", Sensors and Actuators B: Chemical, vol. 297, pp. 126746, June 2019.

15. Vahid Amiri, Hossein Roshan, Ali Mirzaei, Giovanni Neri and Ahmad I Ayesh V, "Nanostructured Metal OxideBased Acetone Gas Sensors: A Review", Sensors, vol. 20, no. 11, pp. 3096, May 2020.

16. Masikini, Milua and Chowdhury, Mahabubur and Nemraoui, Ouassini, "Metal oxides: Application in exhaled breath acetone chemiresistive sensors", Journal of The Electrochemical Society, vol. 167, no. 3, pp. 037537, Jan. 2020 .

17. Kim, Hyo-Joong and Lee, Jong-Heun, "Highly sensitive and selective gas sensors using p-type oxide semiconductors: Overview", Sensors and Actuators B: Chemical, vol. 192, pp. 607-627, march 2014.
18. Lemraski, M Sadeghian and Nadimi, E. Nadimi, "Acetone gas sensing mechanism on zinc oxide surfaces: A first principles calculation", Surface Science, vol. 657, pp. 96103, March 2017.

19. Al-Hadeethi, Yas and Umar, Ahmad and Ibrahim, Ahmed A and Al-Heniti, Saleh H and Kumar, Rajesh and Baskoutas, S and Raffah, Bahaaudin M, "Synthesis, characterization and acetone gas sensing applications of Ag-doped $\mathrm{ZnO}$ nanoneedles", Ceramics International, vol. 43, no. 9, pp. 6765-6770, June 2017.

20. Wang, Jinxiao and Yang, Jun and Han, Ning and Zhou, Xinyuan and Gong, Shuyan and Yang, Jianfeng and Hu, Peng and Chen, Yunfa, "Highly sensitive and selective ethanol and acetone gas sensors based on modified $\mathrm{ZnO}$ nanomaterials", Materials \& Design, vol. 121, pp. 69-76, May 2017.

21. Arun, K and Lekshmi, MS and Suja, KJ, "Design and Simulation of $\mathrm{ZnO}$ based Acetone Gas Sensor using COMSOL Multiphysics",2020 7th International Conference on Signal Processing and Integrated Networks (SPIN), pp. 659-662 Feb 2020, 10.1109/SPIN48934.2020.9070835

22. Liu, Chang and Zhao, Liupeng and Wang, Boqun and Sun, Peng and Wang, Qingji and Gao, Yuan and Liang, Xishuang and Zhang, Tong and Lu, Geyu, "Acetone gas sensor based on $\mathrm{NiO} / \mathrm{ZnO}$ hollow spheres: Fast response and recovery, and low (ppb) detection limit", Journal of colloid and interface science, vol. 495, pp. 207-215, June 2017.

23. Lekshmi MS, Pamula Ravi, Kartik, Akella, Suja, KJ, "Performance analysis of micro hotplate based metal oxide nanowire gas sensor", 2018 7th International Symposium on Next Generation Electronics (ISNE), DOI: 10.1109/ISNE.2018.8394690

24. Farshad Yaghouti, Niyat,M. H., Shahrokh Abad, "COMSOL-Based Modeling and Simulation of $\mathrm{SnO}_{2} / \mathrm{rGO}$, Gas Sensor for Detection of $\mathrm{NO}_{2} "$, Scientific reports, vol. 8, no. 1, pp. 1-12, Feb. 2018.

25. Deepak Punetha,Himanshu Dixit,Saurabh Kumar Pandey, "Modeling and analysis of an Ni:ZnO-based Schottky pattern for $\mathrm{NO}_{2}$ detection", Journal of Computational Electronics, vol. 18, no.1, pp. 300-307, Oct. 2018.

26. Dickinson, E.J.F., Ekström, H., Fontes, Ed: "COMSOL multiphysics: finite element software for electrochemical analysis. A mini-review".,Electrochem. Commun., vol. 40, pp. 71-74, March 2014.

27. Lahlalia, Ayoub and Le Neel, Olivier and Shankar, Ravi and Kam, Shian Yeu and Filipovic, Lado, "Electro-thermal simulation \& characterization of a microheater for SMO gas sensors", Journal of Microelectromechanical Systems, vol. 27 , no. 3, pp. 529-537, June 2018.

28. Kumar, Hardeep and Singh, KK and Sood, Neeru and Kumar, Anuj and Mittal, RK, "Design and simulation of a Micro Hotplate for MEMS based integrated gas sensing system", IEEE Sensors Applications Symposium (SAS), pp. 181- 184, April 2014.

29. Lahlalia, Ayoub and Filipovic, Lado and Selberherr, Siegfried, "Modeling and simulation of novel semiconducting metal oxide gas sensors for wearable devices", IEEE Sensors Journal, vol. 18, no. 5, pp. 1960-1970, Jan. 2018.

30. Vajdi, Mohammad and Moghanlou, Farhad Sadegh and Sharifianjazi, Fariborz and Asl, Mehdi Shahedi and Shokouhimehr, Mohammadreza, "A review on the Comsol Multiphysics studies of heat transfer in advanced ceramics", Journal of Composites and Compounds, vol 2, no. 1, pp. 35-44, April 2020.

31. Karthikeyan Lakshmanan, Akshaya Mouly Vijayakumari, and Palash Kumar Basu, "Reliable and Flow In- 
dependent Hydrogen Sensor Based on Microwave-Assisted ZnO Nanospheres: Improved Sensing Performance Under UV Light at Room Temperature", IEEE sensors journal, vol. 18, no. 5, pp. 1810-1819, Jan 2018.

32. Supab Choopun, Niyom Hongsith and Ekasiddh Wongrat,"Metal-Oxide Nanowires for Gas Sensors" https://www.intechopen.com, pp. 3-24, 2012.

33. Pandeeswari, R and Jeyaprakash, BG,"High sensing response of $\beta$-Ga2O3 thin film towards ammonia vapours: influencing factors at room temperature" Sensors and Actuators B: Chemical, vol 195 pp. 206-214, May 2014.

34. Chiu Hsien $\mathrm{Wu}$, Guo Jhen Jiang, Cheng Chung Chiu, Paul Chong, Chien Chung Jeng,Ren Jang Wu, Jan-Han Chen, "Fast gas concentration sensing by analyzing the rate of resistancechange", Sensors and Actuators B: Chemical, vol. 209, pp. 906-910, March 2015.

35. Das, S., Sarkar, C.K. and Roy, S.," Development of integrated microsystem for hydrogen gas detection". IET Circuits, Devices and Systems, vol. 12, no.4, pp. 453-459, Feb 2018 


\section{Figures}

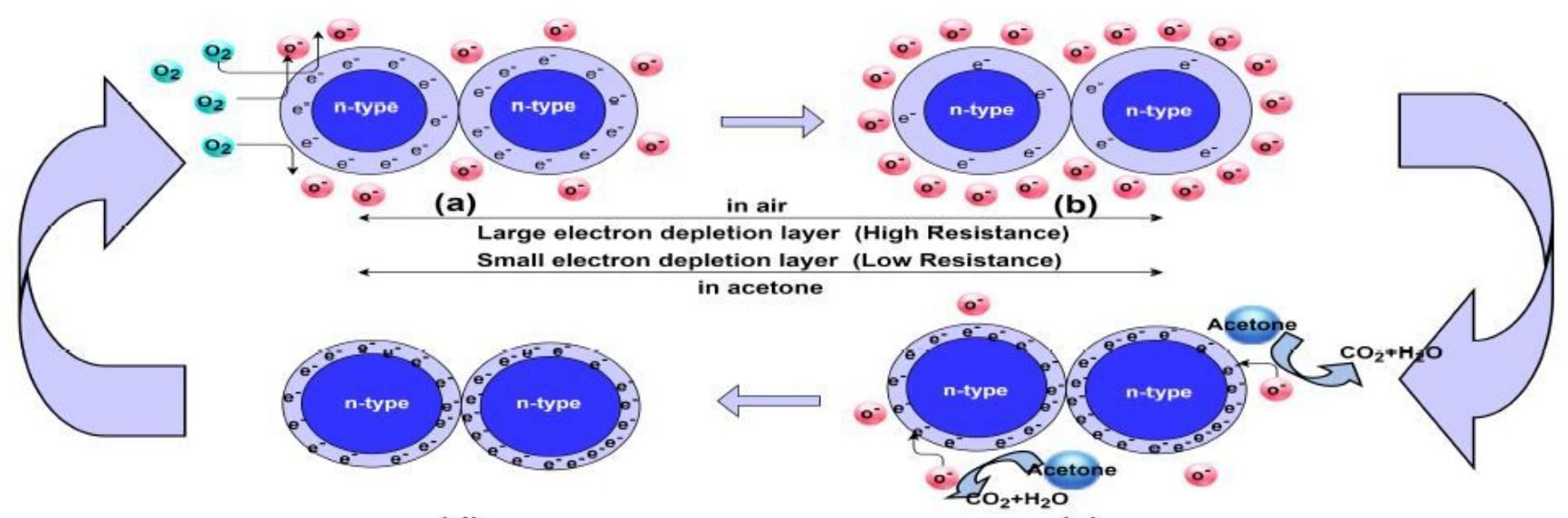

(d)

(c)

\section{Figure 1}

Schematic showing (a) ZnO reaction with the oxygen (b) depletion layer width increases (c) gas sensing mechanism with the acetone gas (d) decrease in potential barrier.

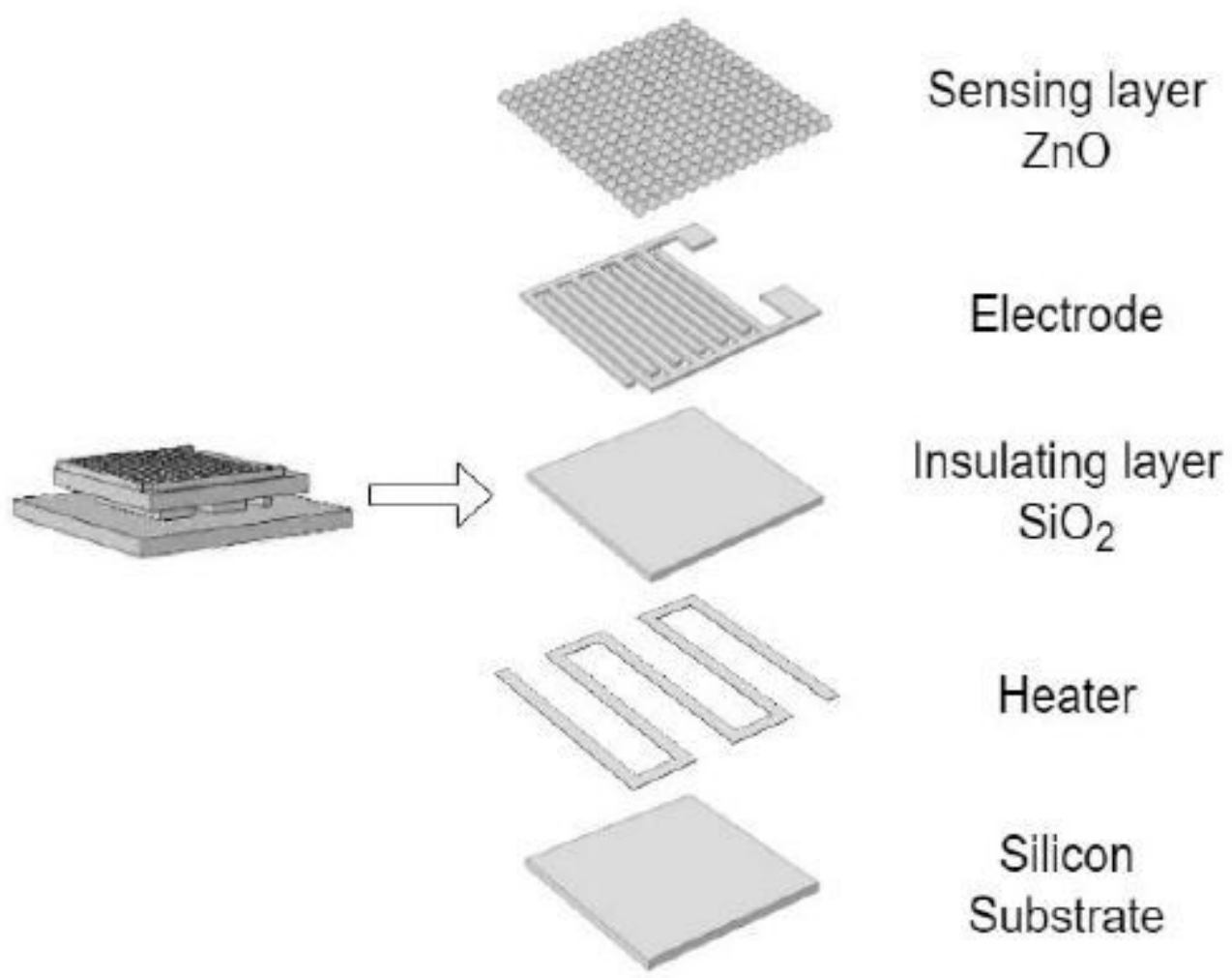

Figure 2

Architecture view model of gas sensor. 


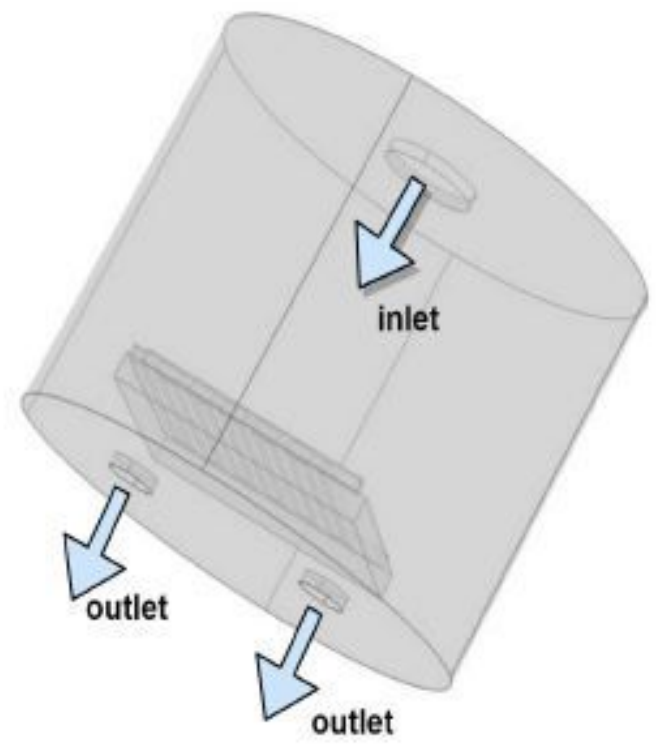

(a)

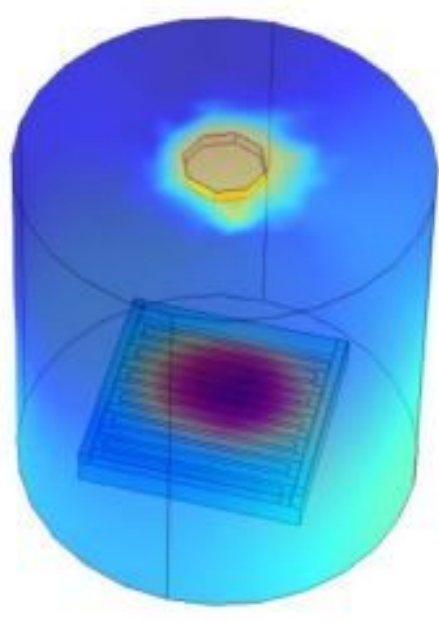

(b)

\section{Figure 3}

Schematic representation of (a) chamber with sensor (b) gas flow distribution in the chamber.

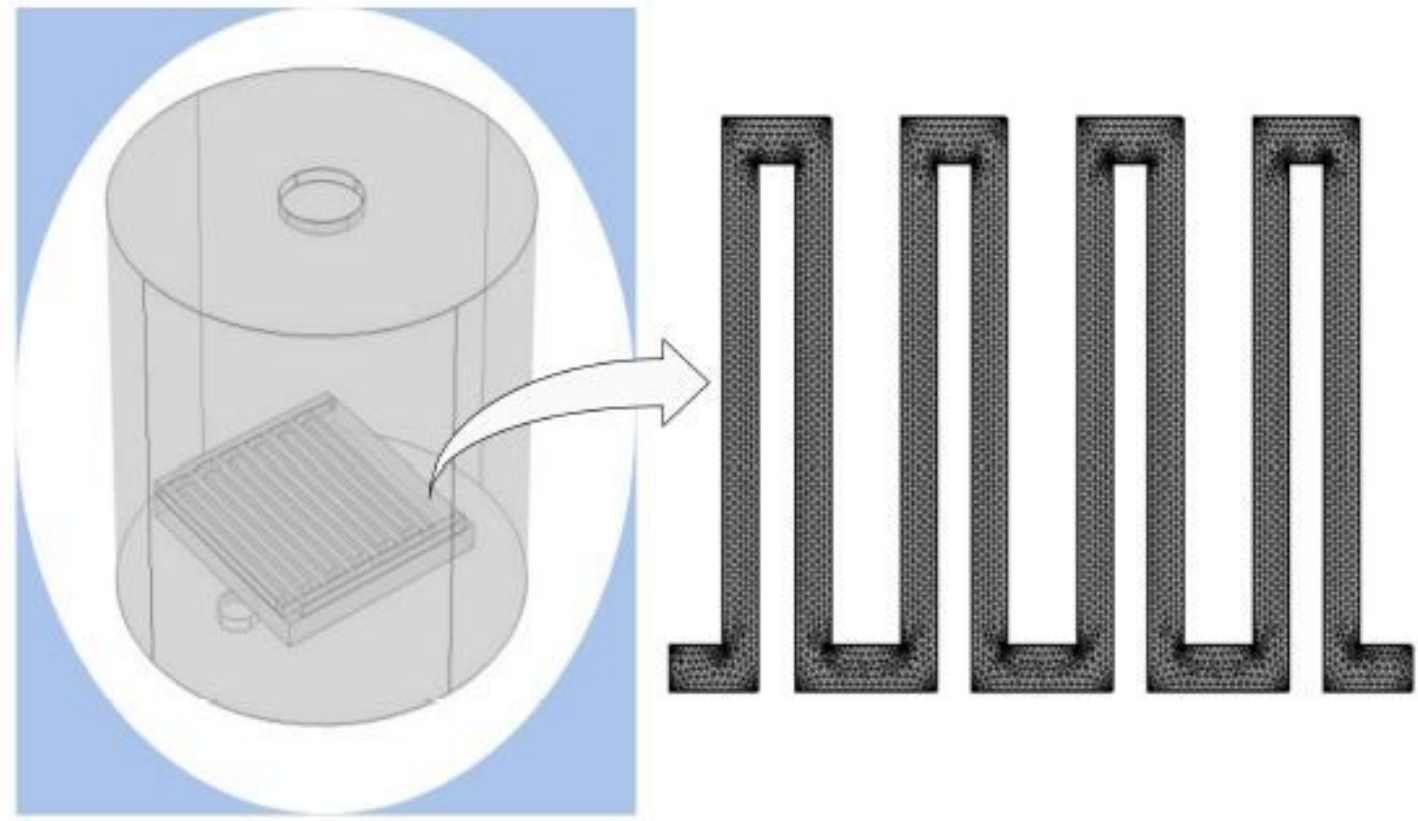

(a)

(b)

Figure 4 
(a)Schematic representation of microheater inside the chamber (b) Simulated microheater.

Time $=25$ s Surface: Temperature $(K)$

$\mu \mathrm{m}$

.00 .25

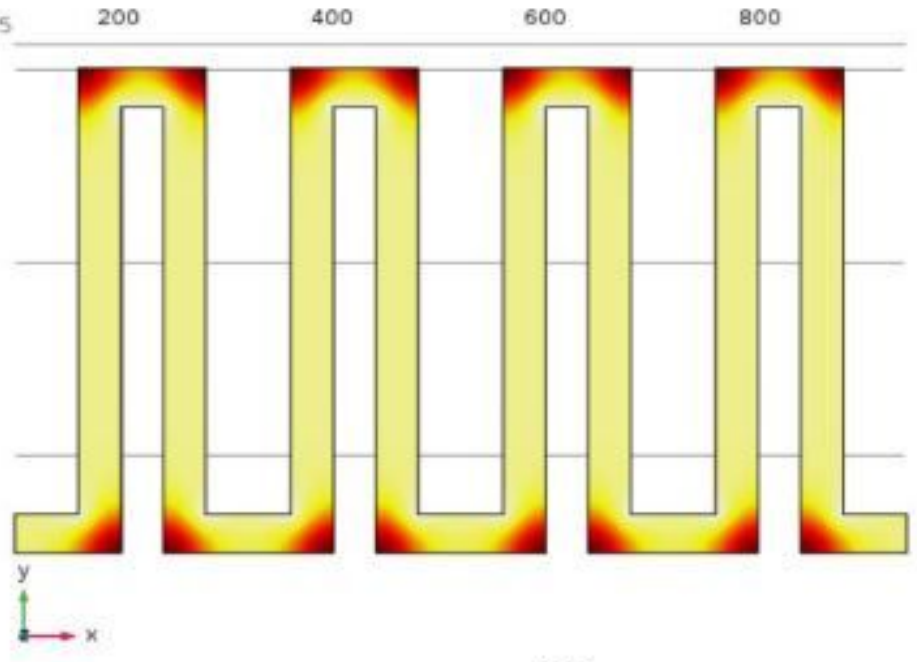

a

A 709

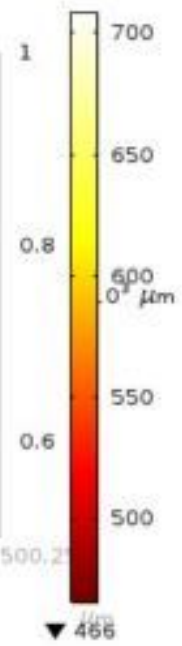

(a)

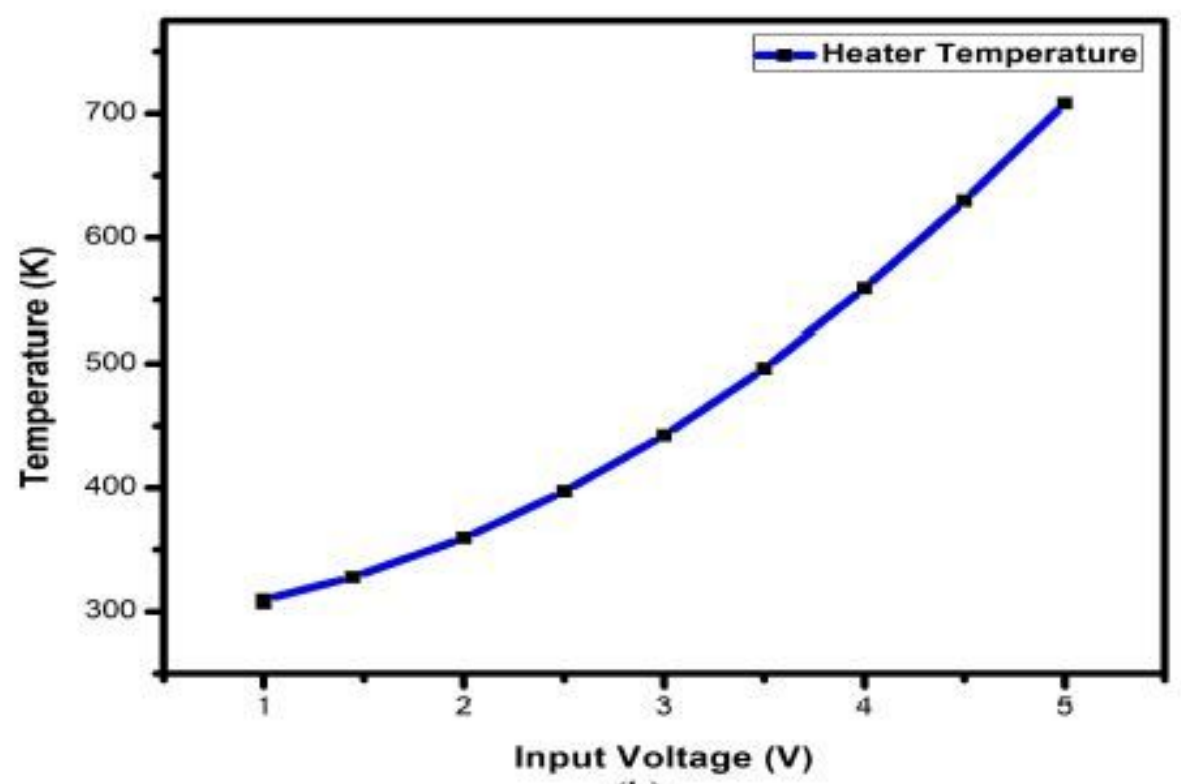

(b)

Figure 5

(a) Heat distribution on the surface of the heater (b) Heater temperature versus applied input voltage. 


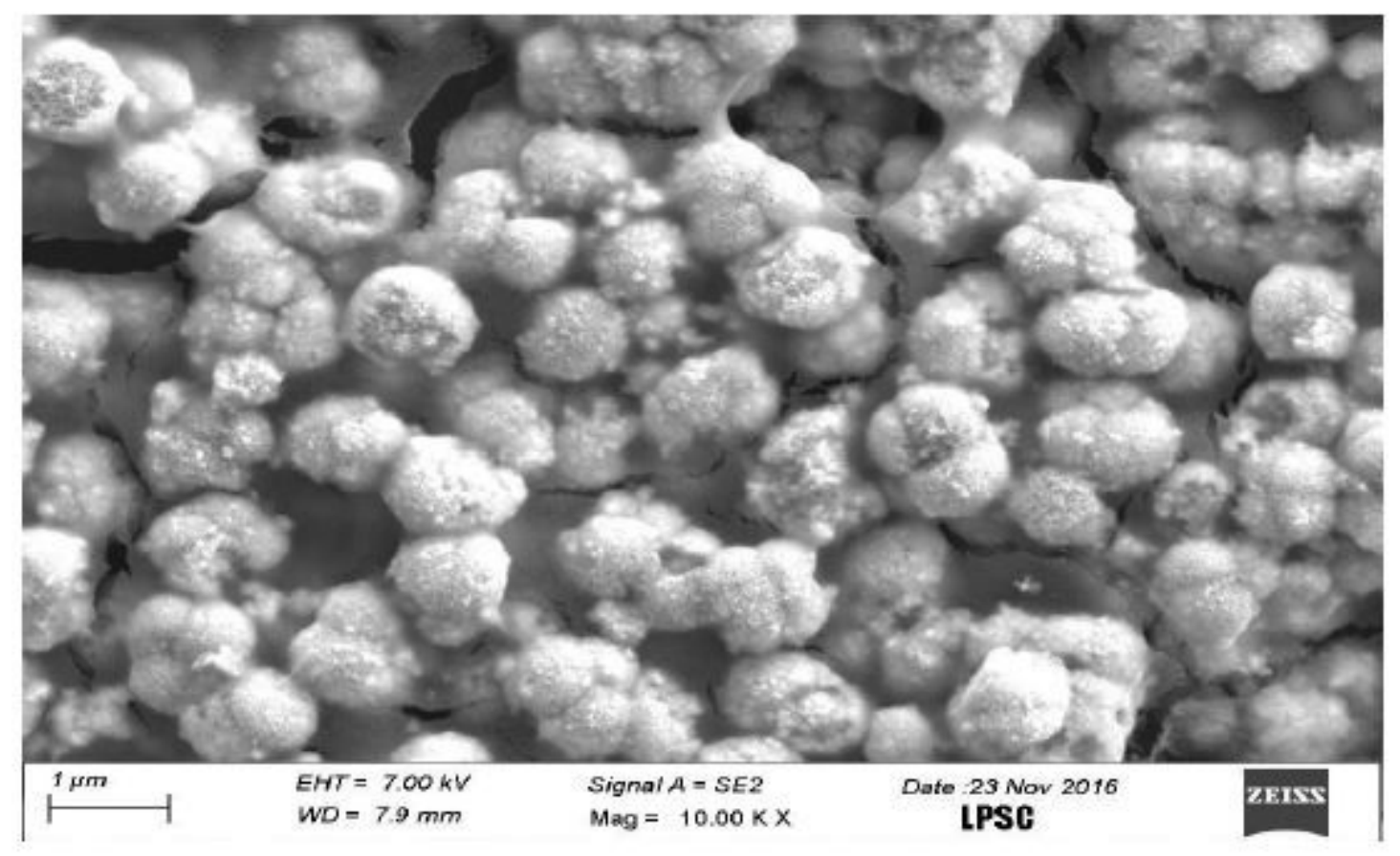

Figure 6

SEM image of Zinc Oxide (ZnO)

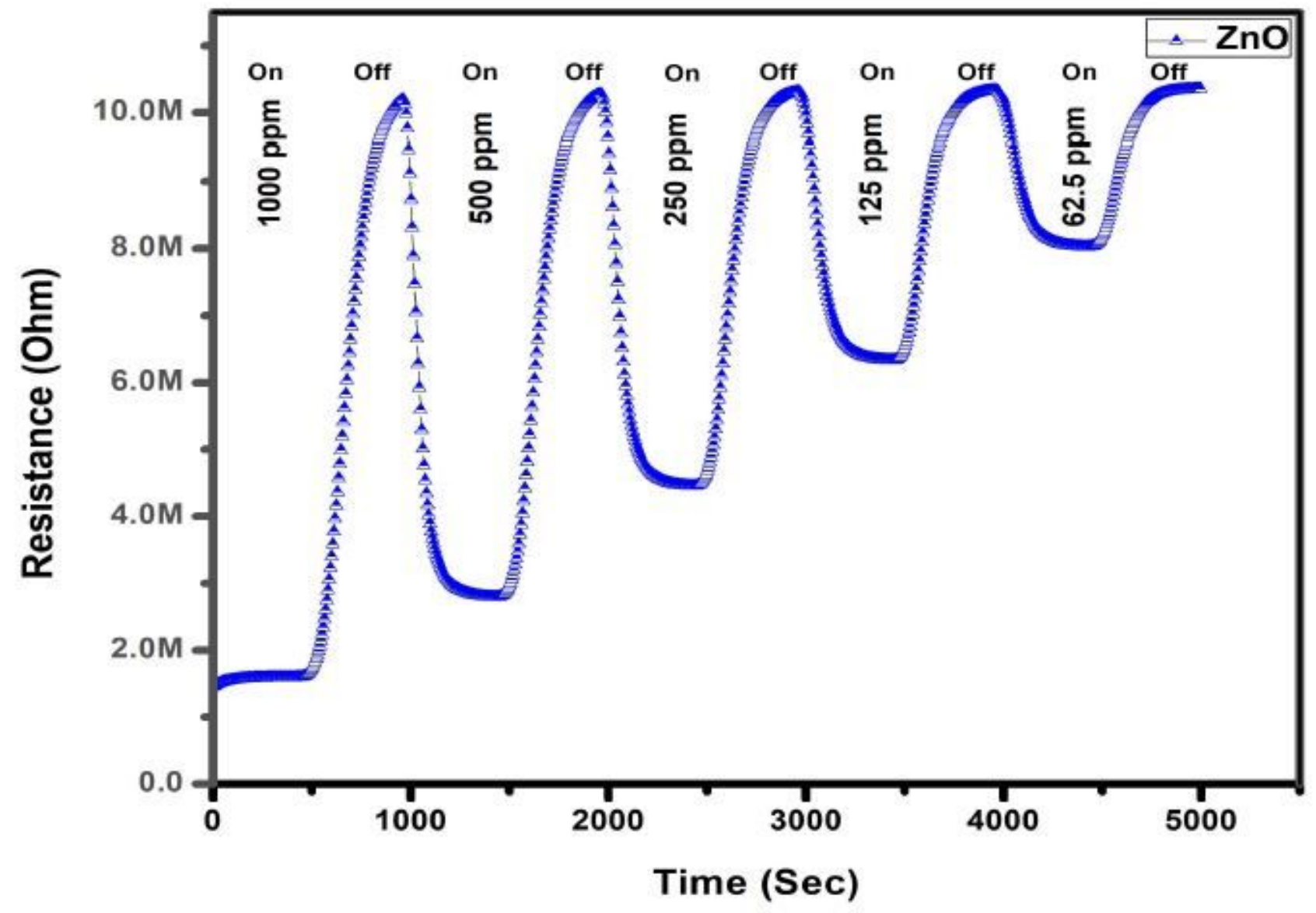


Figure 7

The variation of reistance of $\mathrm{ZnO}$ at different concentration of Acetone gas

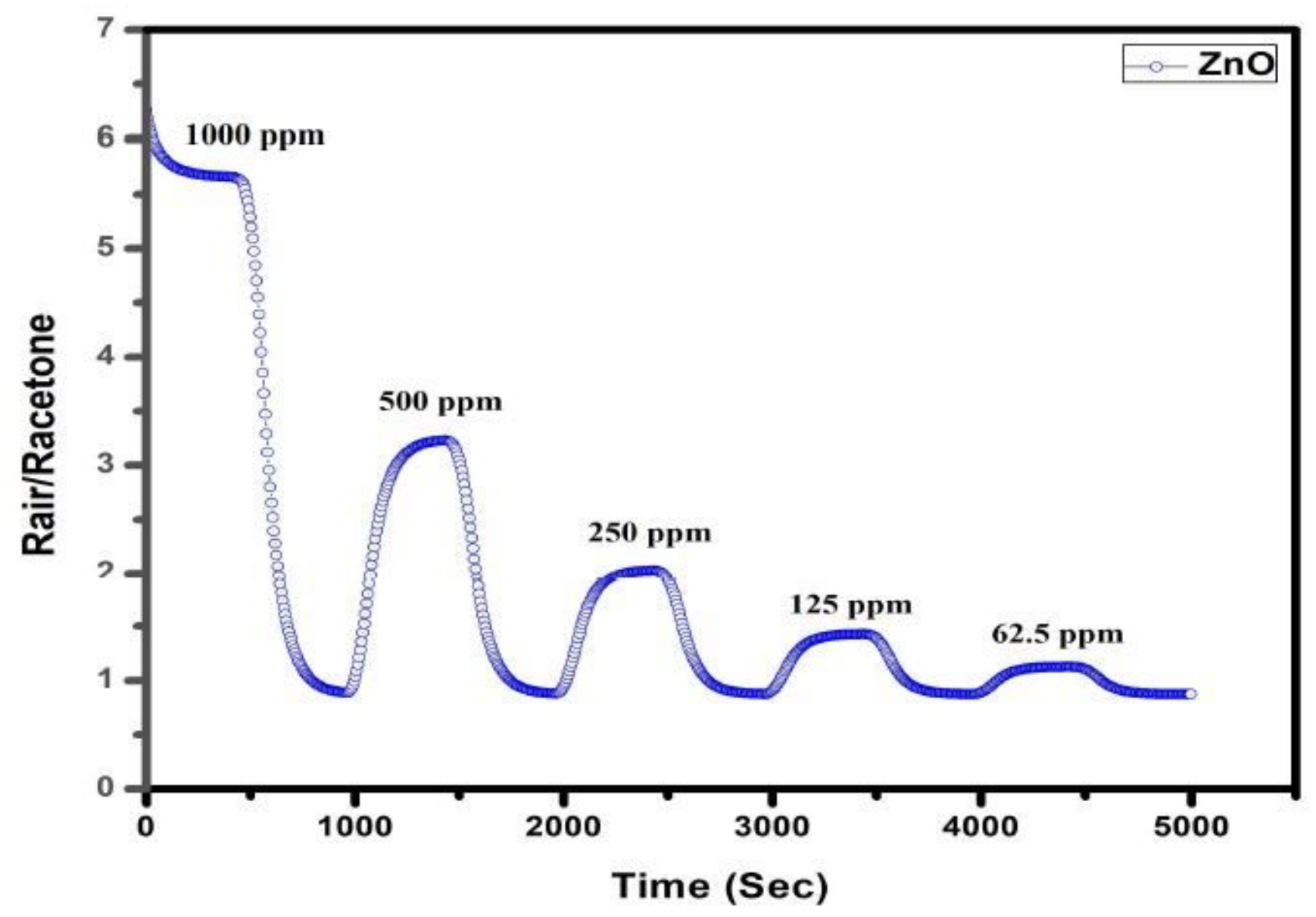

Figure 8

The Time versus Response of $\mathrm{ZnO}$ at different concentration of Acetone gas 


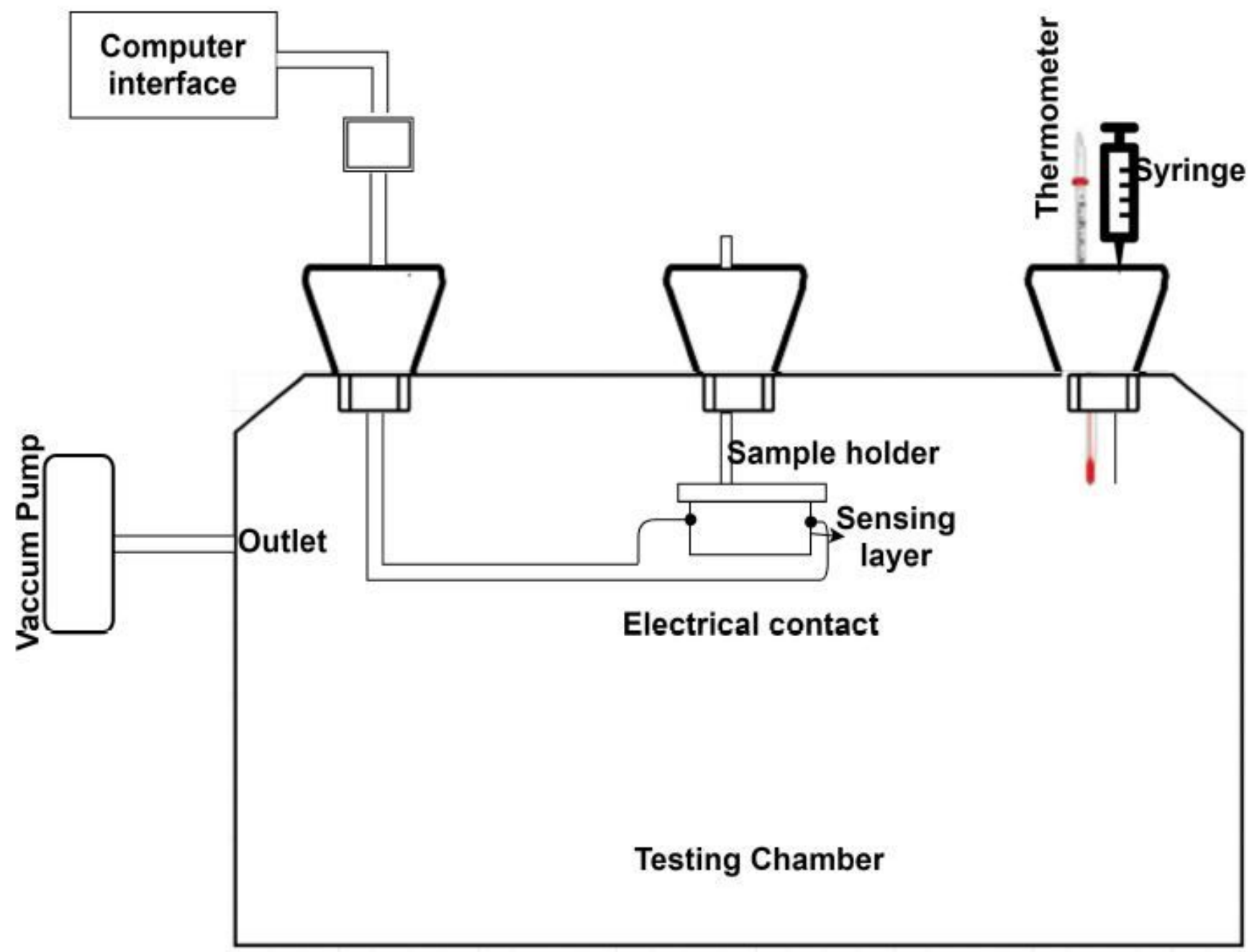

Figure 9

Schematic diagram of experimental sensing setup 


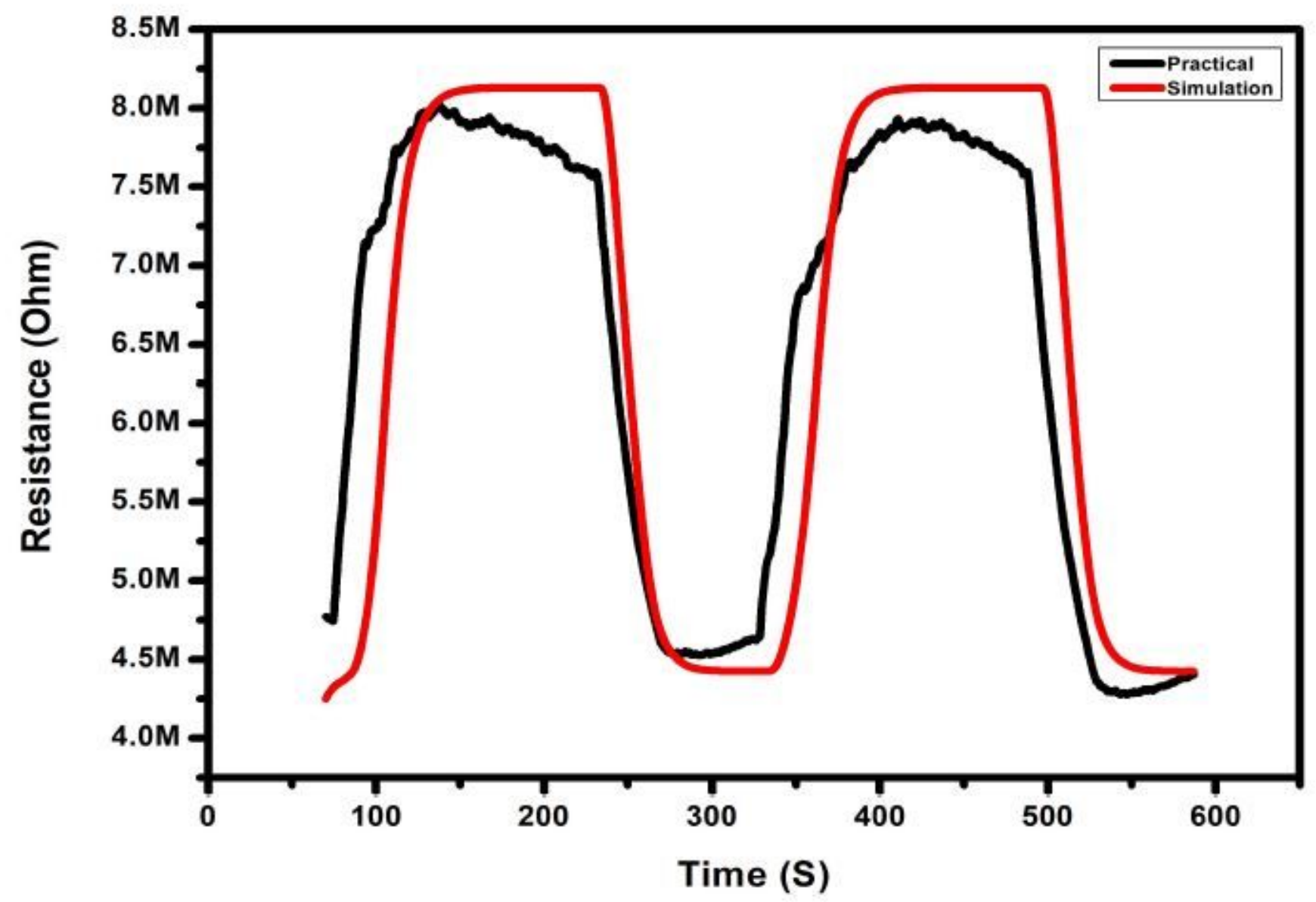

Figure 10

The comparison between practical and simulation data for the variation of resistance of $\mathrm{ZnO}$ at a concentration $1000 \mathrm{ppm}$ of Acetone gas 


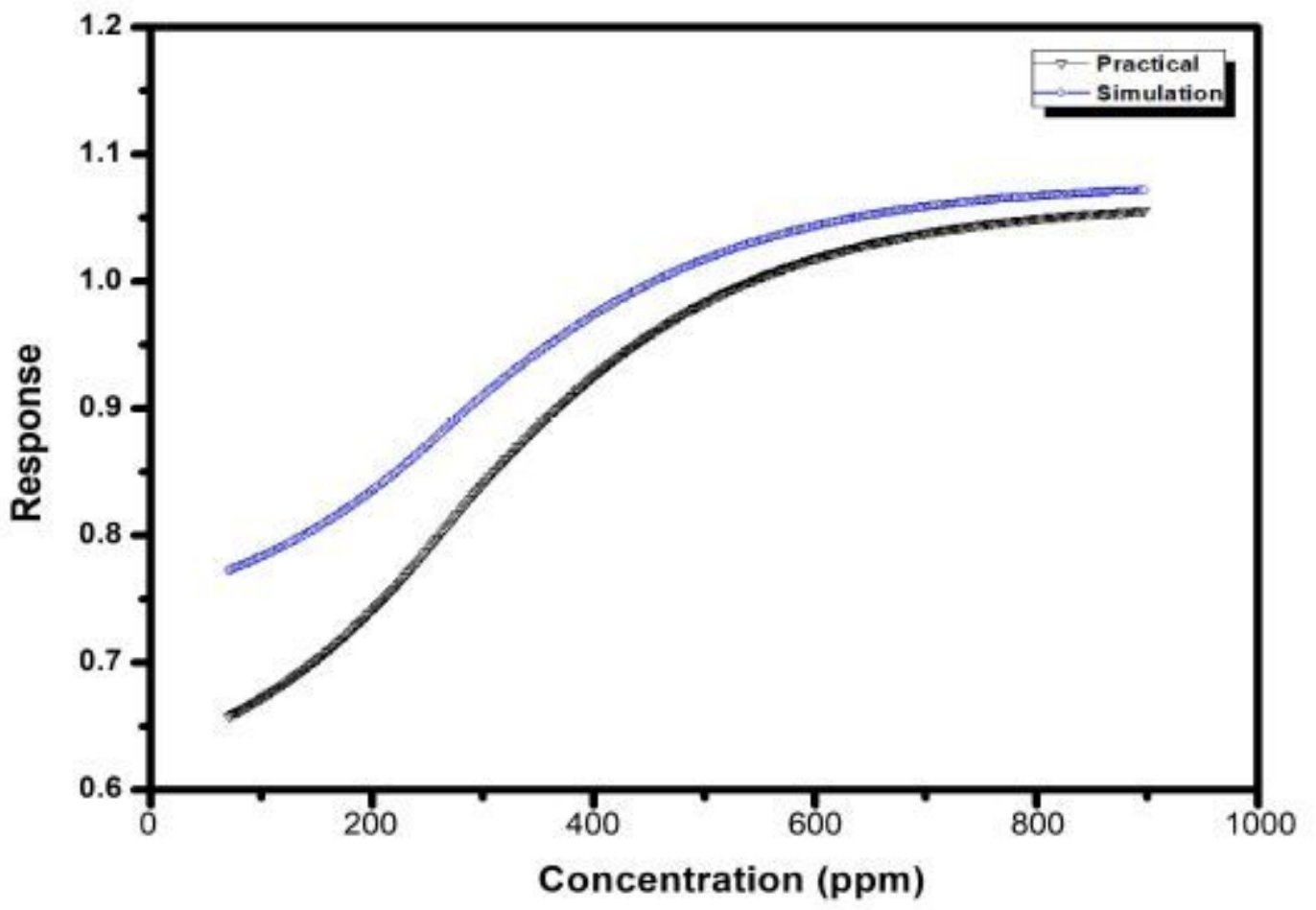

Figure 11

The Concentration versus Response of $\mathrm{ZnO}$.

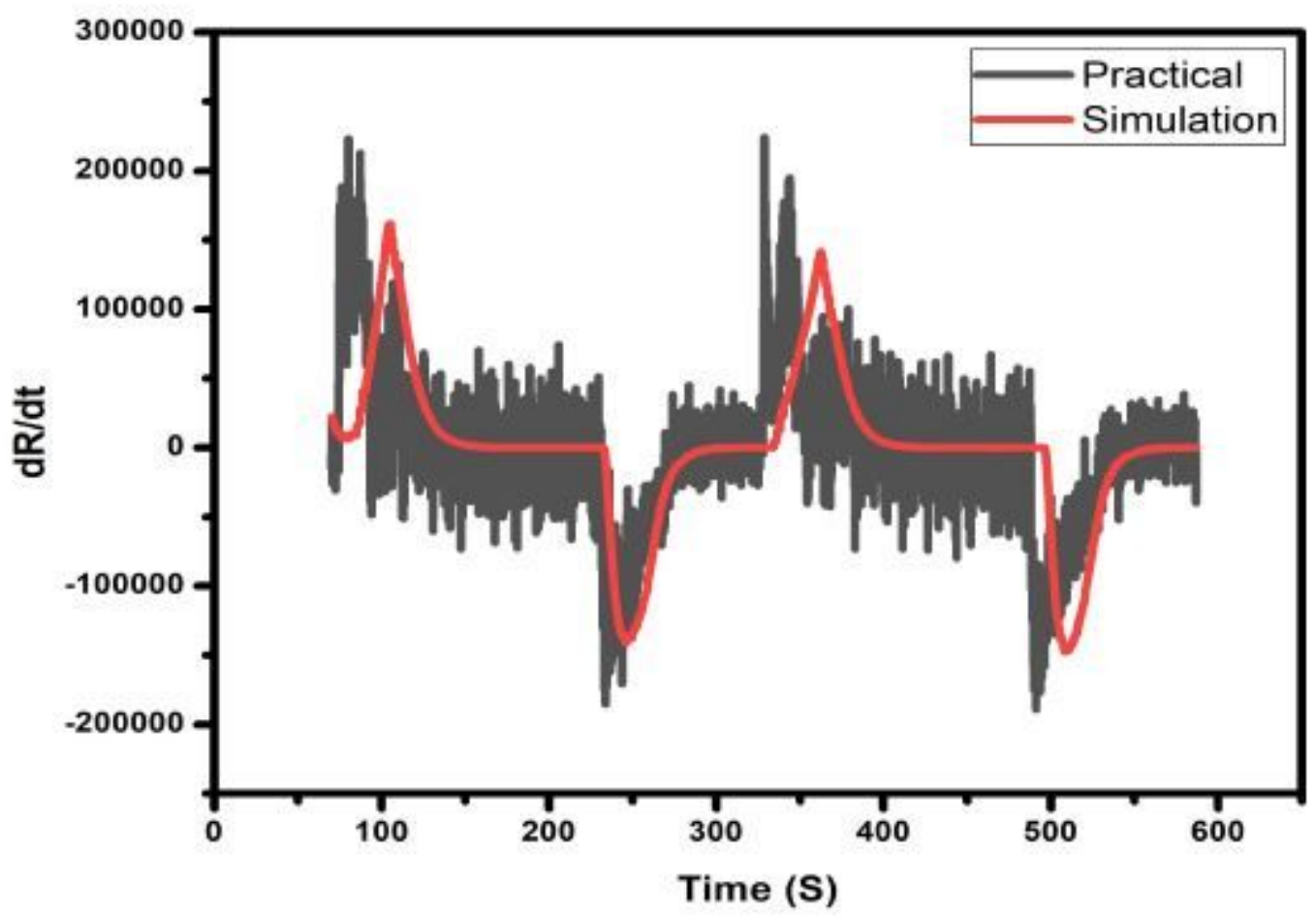

Figure 12

First order derivative curve of resistance time curves of $\mathrm{ZnO}$ sensor at a concentration of $1000 \mathrm{ppm}$. 


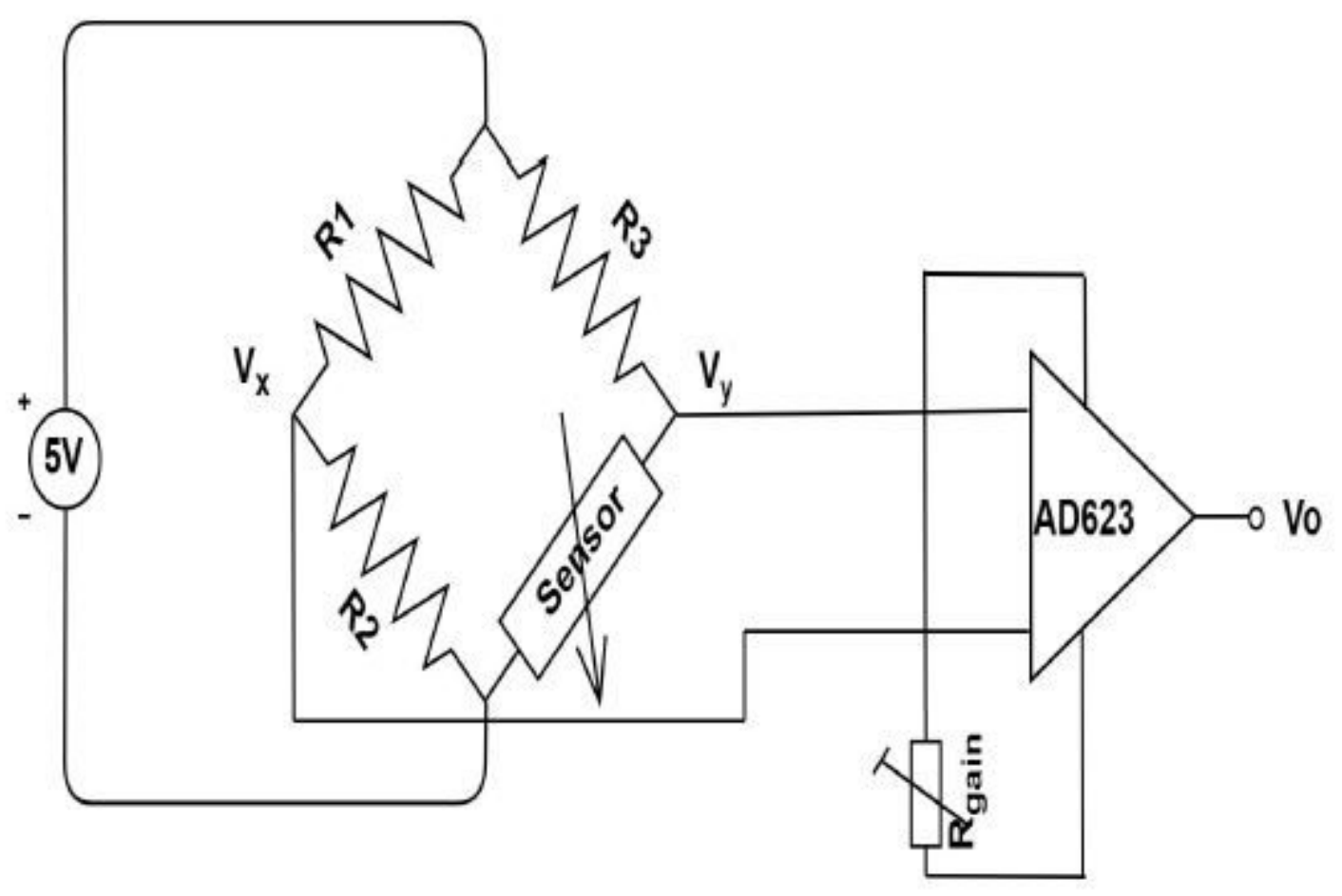

Figure 13

Circuit diagram of signal conditioning unit

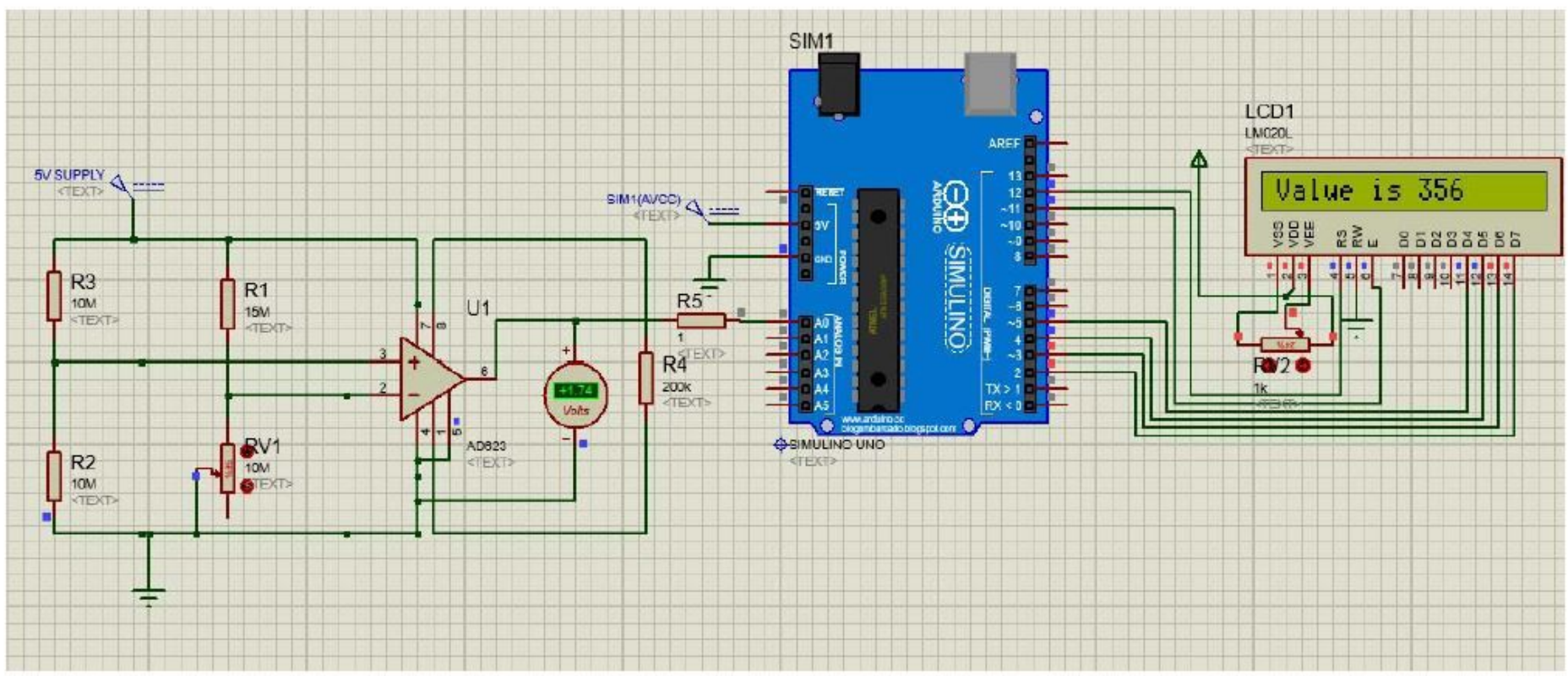

Figure 14

Signal conditioning unit with ADC 